\title{
Martian Subsurface Properties and Crater Formation Processes Inferred From Fresh Impact Crater Geometries
}

\section{Citation}

Stewart, Sarah T., and Gregory J. Valiant. 2006. Martian subsurface properties and crater formation processes inferred from fresh impact crater geometries. Meteoritics and Planetary Sciences 41: 1509-1537.

\section{Published Version}

http://meteoritics.org/

\section{Permanent link}

http://nrs.harvard.edu/urn-3:HUL.InstRepos:4727301

\section{Terms of Use}

This article was downloaded from Harvard University's DASH repository, and is made available under the terms and conditions applicable to Other Posted Material, as set forth at http:// nrs.harvard.edu/urn-3:HUL.InstRepos:dash.current.terms-of-use\#LAA

\section{Share Your Story}

The Harvard community has made this article openly available.

Please share how this access benefits you. Submit a story.

\section{Accessibility}




\title{
Martian subsurface properties and crater formation processes inferred from fresh impact crater geometries
}

\author{
Sarah T. STEWART* and Gregory J. VALIANT \\ Department of Earth and Planetary Sciences, Harvard University, 20 Oxford Street, Cambridge, Massachusetts 02138, USA \\ *Corresponding author. E-mail: sstewart@eps.harvard.edu
}

(Received 22 October 2005; revision accepted 30 June 2006)

\begin{abstract}
The geometry of simple impact craters reflects the properties of the target materials, and the diverse range of fluidized morphologies observed in Martian ejecta blankets are controlled by the near-surface composition and the climate at the time of impact. Using the Mars Orbiter Laser Altimeter (MOLA) data set, quantitative information about the strength of the upper crust and the dynamics of Martian ejecta blankets may be derived from crater geometry measurements. Here, we present the results from geometrical measurements of fresh craters $3-50 \mathrm{~km}$ in rim diameter in selected highland (Lunae and Solis Plana) and lowland (Acidalia, Isidis, and Utopia Planitiae) terrains. We find large, resolved differences between the geometrical properties of the freshest highland and lowland craters. Simple lowland craters are 1.5-2.0 times deeper ( $\geq 5 \sigma_{0}$ difference) with $>50 \%$ larger cavities $\left(\geq 2 \sigma_{0}\right)$ compared to highland craters of the same diameter. Rim heights and the volume of material above the preimpact surface are slightly greater in the lowlands over most of the size range studied. The different shapes of simple highland and lowland craters indicate that the upper $\sim 6.5 \mathrm{~km}$ of the lowland study regions are significantly stronger than the upper crust of the highland plateaus. Lowland craters collapse to final volumes of $45-70 \%$ of their transient cavity volumes, while highland craters preserve only $25-50 \%$. The effective yield strength of the upper crust in the lowland regions falls in the range of competent rock, approximately 9-12 $\mathrm{MPa}$, and the highland plateaus may be weaker by a factor of 2 or more, consistent with heavily fractured Noachian layered deposits. The measured volumes of continuous ejecta blankets and uplifted surface materials exceed the predictions from standard crater scaling relationships and Maxwell's $\mathrm{Z}$ model of crater excavation by a factor of 3 . The excess volume of fluidized ejecta blankets on Mars cannot be explained by concentration of ejecta through nonballistic emplacement processes and/or bulking. The observations require a modification of the scaling laws and are well fit using a scaling factor of $\sim 1.4$ between the transient crater surface diameter to the final crater rim diameter and excavation flow originating from one projectile diameter depth with $Z=2.7$. The refined excavation model provides the first observationally constrained set of initial parameters for study of the formation of fluidized ejecta blankets on Mars.
\end{abstract}

\section{INTRODUCTION}

Impact craters are a natural probe below planetary surfaces. The final shape and size of small, simple crater cavities are determined by the strength and physical properties (e.g., composition, layering, and porosity) of the subsurface materials. The final forms of larger craters are controlled by the gravitational collapse of the shock-weakened rock (Melosh and Ivanov 1999); the transition between the strength regime and gravity regime is proportional to the effective strength of the surface (O'Keefe and Ahrens 1993). Photogrammetry studies of Martian craters determined that the transition between crater formation regimes occurs at smaller crater diameters than expected based on comparisons to Earth, Mercury, and the Moon (Pike 1980, 1988). The smaller transition diameter and shallower crater depths have been interpreted as evidence for the presence of weak, layered, or volatile-rich materials on Mars (Cintala and MouginisMark 1980; Pike 1980). Observed regional variations in a wide range of crater morphologies suggest that Martian crater forms reflect subsurface heterogeneities (Barlow and Bradley 1990).

Perhaps the most intriguing aspect of Martian craters is the range of morphologies observed in their ejecta blankets. 
All fresh and many older Martian craters larger than a few kilometers (Garvin et al. 2002) are surrounded by ejecta blankets that appear to have been fluidized and that then formed a ground-hugging flow. The observed continuous ejecta blankets have a layered appearance with a distal scarp, or rampart, and flow to a radial distance about twice as far as observed on Mercury and the Moon (Mouginis-Mark 1978). While certain rampart-type ejecta have been observed on icy satellites (Horner and Greeley 1982), the diversity of fluidized ejecta morphologies is unique to Mars. The ejecta features are thought to form by entrainment of liquid water (Barlow and Bradley 1990; Carr et al. 1977; Gault and Greeley 1978; Kuz'min et al. 1988; Mouginis-Mark 1981; Stewart et al. 2001, 2004) and/or interactions between the ejecta and the atmosphere (Barnouin-Jha and Schultz 1998; Schultz 1992; Schultz and Gault 1979). Therefore, excavated materials may also provide insight into the composition of the upper crust and perhaps the history of the Martian climate. However, the physical processes that control the formation of fluidized ejecta morphologies are still poorly understood (Barlow et al. 2005).

Recent crater studies have used the Mars Orbiter Laser Altimeter (MOLA) global topography data to deduce more accurate size and shape scaling relationships (Garvin and Frawley 1998; Garvin et al. 2003), to study gradational forms (Garvin et al. 2000), to investigate the sedimentary history of the northern plains (Black and Stewart, Forthcoming; Boyce et al. 2005a, 2005b; Forsberg-Taylor et al. 2004; Meresse et al. 2005), and to infer the age of buried surfaces (Frey et al. 2002b). The topography data also allow for quantitative comparisons between final ejecta geometries and ejecta flow processes (Barnouin-Jha et al. 2005).

Geometrical measurements of Martian craters may also be used to study the final stages of crater collapse. Crater scaling laws relate the impact conditions to the transient crater cavity and have been validated by impact and explosion experiments and numerical simulations (Holsapple 1993; O'Keefe and Ahrens 1993; Schmidt and Housen 1987). The observed crater cavities, however, are a result of the collapse of the transient cavity, which is still an area of intense study in impact-cratering mechanics. The collapse of simple craters is dominated by crater-wall slumping (Grieve and Garvin 1984), but the collapse of complex craters is much more complicated (Melosh and Ivanov 1999). The observed differences between Mars and other rocky bodies may be illuminated by close examination of Martian crater geometries and comparison to crater scaling laws.

The MOLA topography data allow, for the first time, accurate measurement of the volume of ejecta around Martian craters. Initial studies discovered that the ejecta volume around some Martian craters is larger than can be explained by the size of the excavated cavity (Garvin and Frawley 1998). Excess ejecta volume could be explained by concentration of excavated materials into the continuous ejecta blanket, bulking, and/or incorporation of surface materials into the ejecta flow. The processes controlling the formation of fluidized ejecta depend critically on the total mass and source materials for the flow. Detailed comparisons between predicted excavation volumes and observed ejecta volumes will constrain the initial conditions for Martian ejecta flow dynamics.

This study focuses on deriving quantitative information about the strength of the Martian crust, including regional variability and the formation of fluidized ejecta morphologies through analyses of fresh impact crater geometries. We measure several geometrical properties of impact craters using the MOLA data set and a new crater measurement interactive toolkit (Valiant and Stewart 2004). In the "Crater Measurement Methods" section, measurement methods are described and the accuracy and precision of the toolkit are determined from measurements of simulated craters on a range of Martian background terrains and at different MOLA track resolutions. In this work, we focus on fresh craters in highland and lowland plains, where crater geometry measurements are most accurate. In the "Crater Measurements Results" section, we describe large, resolved differences in fresh crater geometries between lowland plains regions (Utopia and Isidis basins and Acidalia Planitia) and highland plateau regions (Lunae and Solis Plana). In the "Implications for Martian Subsurface Properties" section, we infer the differences in material strength in the studied highland and lowland terrains using crater size scaling relationships and discuss the origin of near-surface layers of differing strength. In the "Ejecta Volumes and the Z-EDOZ Model" section, the volumes of ejected and uplifted materials are compared to crater excavation models and we discuss the implications for the formation of fluidized ejecta blankets. The major conclusions from this work are summarized in the "Conclusions" section, and a description of variables is included in Appendix A.

\section{CRATER MEASUREMENT METHODS}

\section{Measurement Toolkit}

Crater measurements are executed using the HMars interactive toolkit, a graphical, cross-platform program written in the Interactive Data Language (IDL), shown in Fig. 1. The data used for crater measurements are the Precision Experiment Data Records (PEDR) altimetry profiles (version L in IAU2000 coordinates) from the Mars Orbiter Laser Altimeter (MOLA) experiment on the Mars Global Surveyor spacecraft (Smith et al. 2001). Digital elevation maps (DEMs) are derived from the altimetry profiles using the Delaunay triangulation function as implemented in IDL (Lee and Schachter 1980). DEMs are generated on the fly at the user-specified spatial resolution for the region of interest. Individual outlier altimetry tracks may 
be removed interactively, with recalculation of the DEM. To speed the generation of DEMs, the time sequence of altimetry profiles was reorganized into regional data sets on a $25 \times 25$ global grid with no change to the original PEDR data. Each MOLA altimetry point covers a spot on the surface $\sim 168 \mathrm{~m}$ in diameter with a vertical accuracy of $\sim 1 \mathrm{~m}$ (Smith et al. 2001). Measurements on individual craters are conducted at a minimum resolution of 40 pixels per crater rim diameter and usually at a resolution at the limit of the $300 \mathrm{~m}$ along-track spacing of the MOLA altimetry profiles.

The crater features measured by HMars are illustrated in Fig. 2. Measurements of the crater rim diameter, $D_{\mathrm{R}}$, and rim height, $H_{\mathrm{R}}$, are derived from altimetry tracks. Measurements relative to the preimpact surface, i.e., the surface depth, $d_{\mathrm{S}}$, and the surface diameter, $D_{\mathrm{S}}$, are based on the DEMs. All volume measurements are calculated from the gridded data set. The crater depth from the rim, $d_{\mathrm{R}}$, is the sum of the surface depth and rim height.

For each crater, the user interactively estimates the location of the crater center and rim diameter. The userestimated crater center is refined by convolving a ring with the topography gradient rather than fitting irregular rims with an ellipsoid. The crater radius, rim uplift height, and their variances are calculated by interpolating the rim location and maximum rim height along each altimetry track that passes within a specified fraction (e.g., 0.8) of the estimated crater radius to the estimated center. The highest track point near the rim, three points downrange, and three points uprange are fit with two quadratic functions to determine the intersection between the crater wall and the outer rim wall. The highest track point, which usually underestimates the true rim height, and the number of rim points used to calculate the rim diameter and rim height are also recorded in the crater data record.

The background preimpact surface is derived from userspecified tie points beyond the edge of the ejecta blanket, shown as "+" in the example in Fig. 1. The tie points are interpolated by Delaunay triangulation across the crater cavity and ejecta blanket. We investigated different fitting procedures to define the preimpact surface (e.g., polynomial surfaces), but found that the Delaunay triangulation performed well on the simulated crater data sets (discussed below). In uneven terrain, particular care is required by the user to select background surface tie points that best represent the overall slope and roughness of the region. In addition, users may limit the area of integration surrounding the crater by tracing an outer edge to the region defined by the background tie points (outer solid white line in Fig. 1). When a background feature, e.g., a preexisting crater, lies just beyond the edge of the ejecta blanket, the best tie points for the preimpact surface may surround both craters. The edge of region definition then excludes the preexisting crater from the measurements. An example of a crater DEM with the background subtracted and edge of region definition is shown in Fig. 3a.
The cavity volume from the preimpact surface, $V_{\text {Cavity, }}$ the cavity volume from the rim, $V_{\text {Rim }}$, and the volume of ejecta and uplifted material, $V_{\text {Above }}$, are derived by integrating the DEM over the areas interior and exterior to the crater rim, respectively. Preimpact features or sparse data coverage may interfere with an accurate measurement of the volume of ejecta and uplifted material surrounding the crater. In these cases, one or more user-defined pie-shaped wedges may be used to exclude an area from integration (Figs. 1 and 3). The volume in the excluded region is set to zero, and the total volume measurements are adjusted to compensate for the missing area assuming axisymmetry.

Measurement of the continuous ejecta blanket volume, $V_{\text {Ejecta, }}$ requires knowledge of the profile of the deformed preimpact surface surrounding the crater. For simple bowlshaped craters, the surrounding topography is uplifted and forms a portion of the crater rim. In this case, the preimpact surface can be estimated by connecting a fraction of the rim height with the surface beyond the ejecta blanket. For larger complex craters, however, the process of crater collapse may result in little or no deflection of the preimpact surface outside the final crater rim (Melosh and Ivanov 1999). In this study focusing primarily on fresh, simple, and transition-sized craters with well-preserved rims, we estimate the maximum possible uplifted surface by a power law that lies just beneath the ejecta profile, as shown in Fig. 2 . Hence, $V_{\text {Ejecta }}$ provides a lower limit to the ejecta volume, and $V_{\text {Above }}$ is the upper limit. If regions of the ejecta blanket are excluded with pie-shaped wedges, the value of $V_{\text {Ejecta }}$ is also increased accordingly. Figure $3 \mathrm{~b}$ displays the volume of ejecta after subtraction of the model uplifted surface. The uplifted surface height, $h_{\mathrm{u}}$, is defined by $h_{\mathrm{u}}=0.5 H_{\mathrm{R}}\left(r / R_{\mathrm{R}}\right)^{-5.5}$ based on Martian cratering simulations (Stewart et al. 2004), where $r$ is the radial distance from the crater center and $R_{\mathrm{R}}$ is the crater rim radius. The uplift profile is discussed in more detail in the "Comparison to Observations and Improving the Scaling Relationships" section. In the example in Fig. 3b, a portion of the eastern rim has been oversubtracted, producing negative thickness in the ejecta blanket. The irregularities in the rim and gaps in the altimetry data result in volume errors near the crater rim, which are small compared to the overall uncertainty in the uplifted surface.

As part of the data entry for each crater, the user traces the distal edge of the ejecta and, if a double or multiple layer rampart crater, the inner rampart (inner solid white line in Fig. 1). The user consults the Viking Mosaicked Digital Image Model (MDIM) and Thermal Emission Imaging System (THEMIS) imagery to aid the identification of features in the ejecta blanket. The HMars toolkit also includes several visualization aids such as generation of 2-D and 3-D shaded relief views of the DEM, viewing of track coverage, and viewing of along-track altimetry profiles and arbitrary profiles across the DEM. Following the guidelines of Barlow et al. (2000), the user classifies each crater ejecta type as either i) no rampart, ii) single rampart, iii) double rampart or 


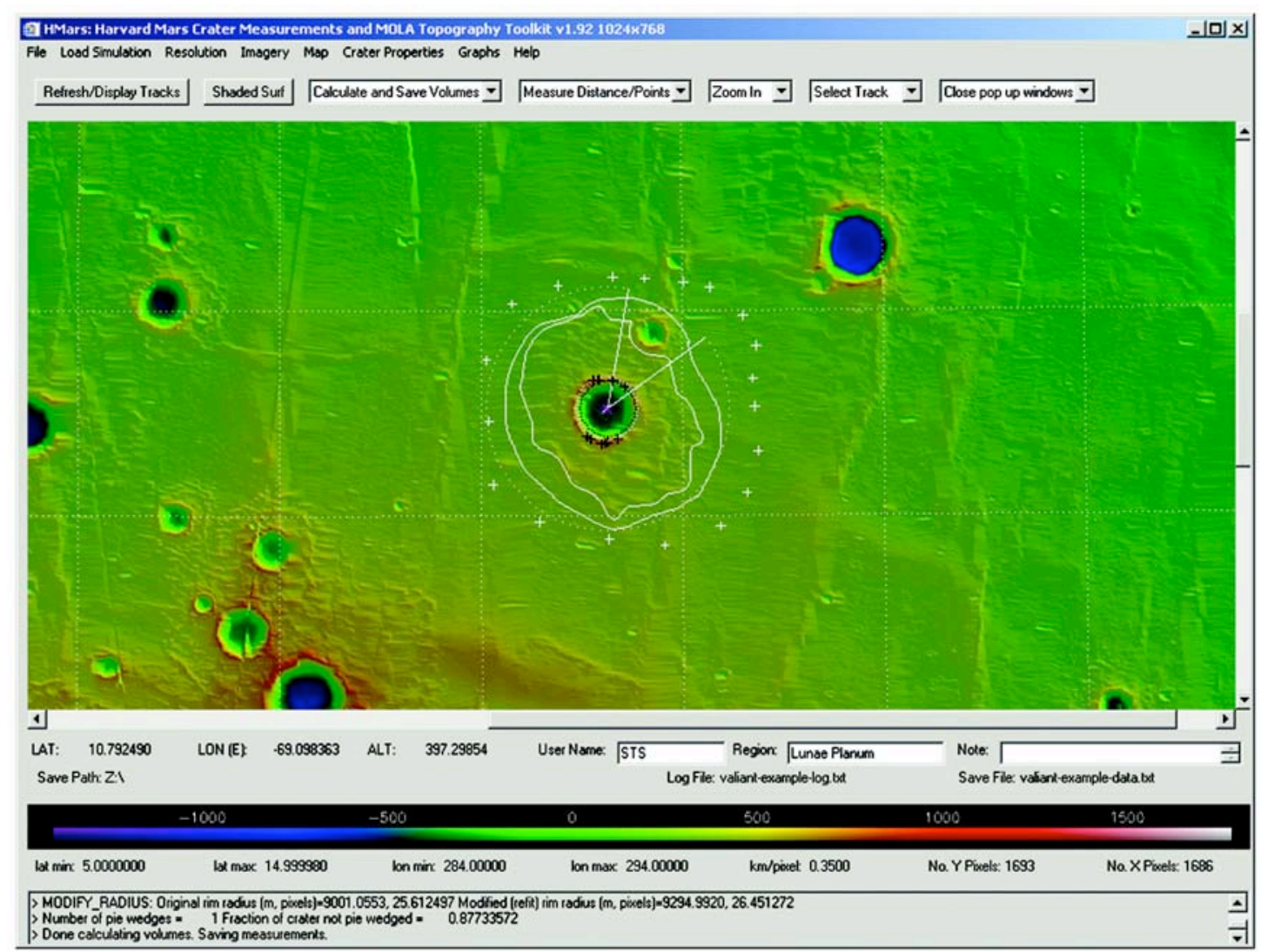

Fig. 1. A screen shot of the HMars interactive crater measurement program.

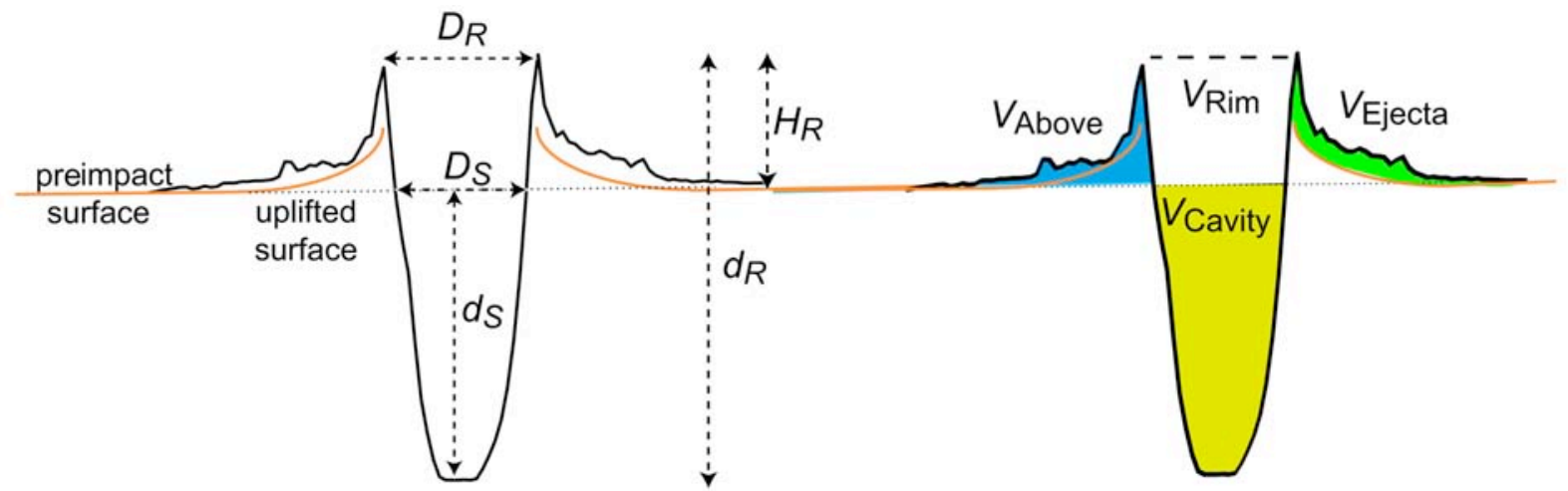

Fig. 2. Measured crater attributes in HMars. $D_{\mathrm{R}}=$ rim diameter; $D_{\mathrm{S}}=$ surface diameter; $d_{\mathrm{R}}=$ rim depth; $d_{\mathrm{S}}=$ surface depth; $H_{\mathrm{R}}=$ rim height; $V_{\text {Cavity }}=$ volume of cavity below preimpact surface; $V_{\mathrm{Rim}}=$ volume of cavity below the rim level; $V_{\text {Above }}=$ volume of ejecta and uplifted material; and $V_{\text {Ejecta }}=$ volume of ejecta only. Profile of a $D_{\mathrm{R}}=8 \mathrm{~km}$ crater from Lunae Planum $\left(11.6^{\circ} \mathrm{N}, 72.4^{\circ} \mathrm{E}\right)$. Vertical exaggeration (V.E.) is $24: 1$.

multiple ramparts, iv) radial ejecta, or v) severely eroded ejecta. The gradation state of each crater is described qualitatively by the user as i) fresh, ii) moderately degraded (partial infill/partial ejecta erosion), iii) heavily degraded (significant infill and/or ejecta erosion), or iv) severely degraded (complete infill and rim erosion).

The approximately 30 crater measurements and observations are stored in a data structure with a keyword and value format. The final crater database is a list of data structures in ASCII format. The user-defined traces of ejecta ramparts are stored in a binary IDL save file. Each crater measurement also generates a $\log$ file, which records all the user inputs and interactive selections. Each crater measurement may be recreated using the log file, e.g., to test different fitting algorithms for the same user inputs or to investigate an anomalous measurement. 

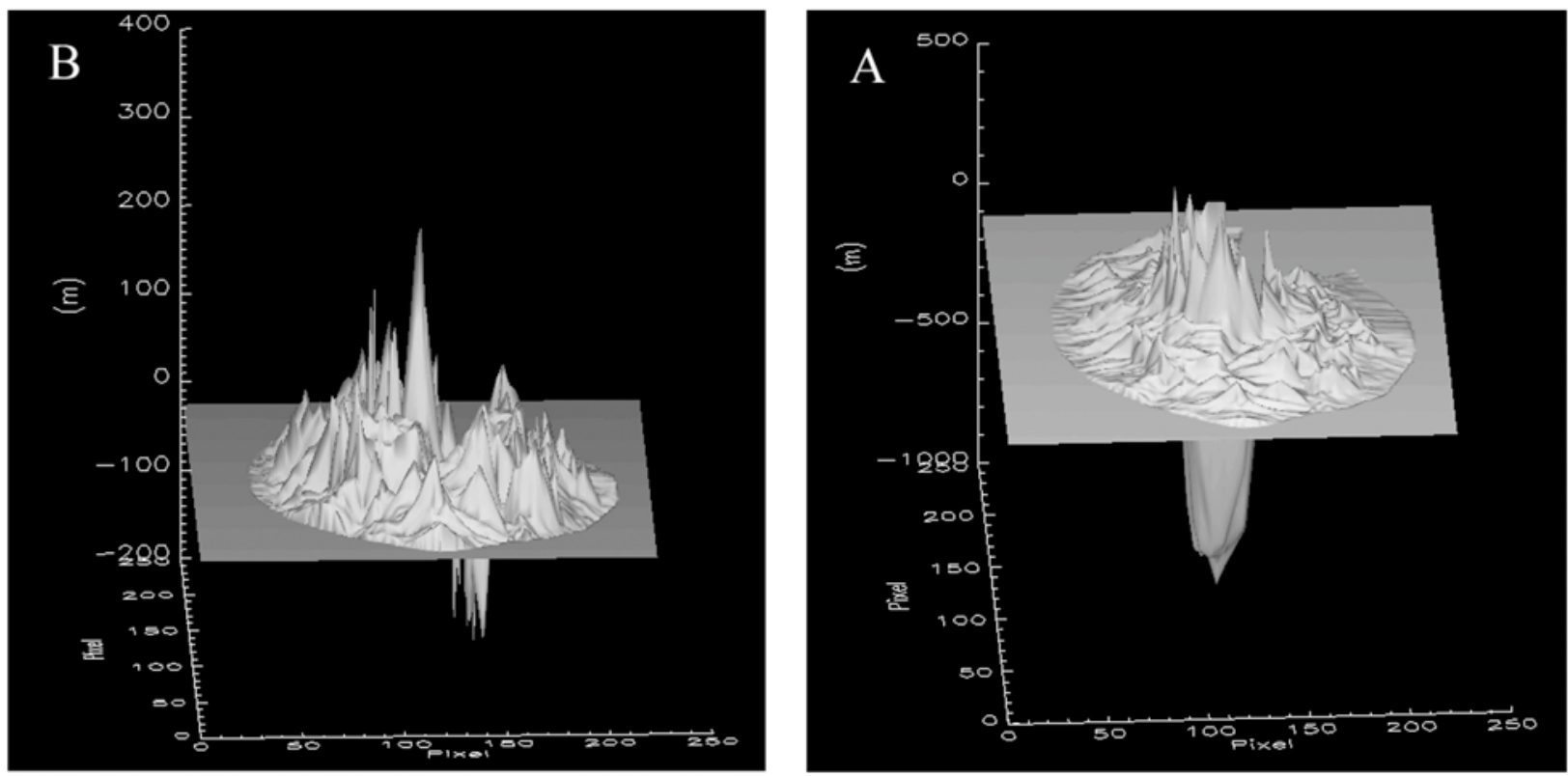

Fig. 3. a) A shaded relief perspective view of the crater DEM from Fig. 1 with the preimpact surface subtracted. Zeroed pixels on the DEM lie beyond the user-defined edge of the region. V.E. = 15:1. b) DEM of ejecta blanket with uplifted surface subtracted. V.E. $=37.1$. DEM resolution is $350 \mathrm{~m} /$ pixel.

\section{Resolution and Measurement Tests}

The HMars toolkit was tested for systematic errors, resolution limits, and reproducibility. We conducted measurements of simulated craters on different background terrains and verified that no systematic offsets were present in the crater measurements. The resolution limits and standard deviation for each measurement were derived by varying the altimetry track density on simulated craters on different terrains. The reproducibility was tested by comparison to published crater geometry measurements and comparing measurements by different users.

DEMs of simulated fresh craters were generated on a flat background surface at spatial resolutions comparable to the MOLA track density at high latitudes. The simulated crater sets are composed of 15 craters each in 8 size bins between 2 and $50 \mathrm{~km}$ rim diameter. The model craters were created using analytic functions for the height of the uplifted preimpact surface, described by $\left(r / R_{\mathrm{R}}\right)^{-5.5}$, and crater cavity depth, modeled with $\left(r / R_{\mathrm{R}}\right)^{4}$. The rim uplift model was derived from impact cratering calculations (Stewart et al. 2004). The rim uplift is sensitive to the target material properties, and the uncertainties in applying a rim uplift model to the Mars data are discussed in the "Comparison to Observations and Improving the Scaling Relationships" section. The simulated rim height was typically several percent of the rim diameter for small craters, dropping to about a percent for the largest craters. The simulated crater depth was a third of the crater rim diameter for the smallest craters, and decreased to several percent for the largest craters. The simulated crater set contains both single- and double-layer rampart ejecta. The exact ejecta thickness and range were randomly generated over a realistic range of parameters. The single-layer ejecta thickness was given by $\sin ^{2}\left(r^{2}\right)$ for $r=0$ to $\pi^{0.5}$. Double-layer ejecta are described by a piecewise function with an exponential section and ending with a $r^{0.2}$ profile. Examples of the simulated craters are shown in Fig. 4.

The simulated craters' DEMs were sampled to create synthetic altimetry track profiles. Three track densities were simulated: the low track density used actual altimetry tracks from the equatorial region on Mars, the medium track density had double the number of tracks, and high track density had four times the number of tracks. The three synthetic altimetry track densities are representative of the MOLA data coverage at the equator, mid-, and high latitudes. Four background surfaces were created to test the HMars toolkit. We considered an ideal flat background and three backgrounds generated by tiling patches from regions on Mars with few large craters that are representative of the study regions in this work. The backgrounds are centered at i) $33^{\circ} \mathrm{N}, 200^{\circ} \mathrm{E}$ (Arcadia Planitia); ii) $7^{\circ} \mathrm{N}, 290^{\circ} \mathrm{E}$ (Lunae Planum); and iii) $32^{\circ} \mathrm{N}, 98^{\circ} \mathrm{E}$ (Utopia Planitia). Each background surface was also sampled to create altimetry profiles at each track density. For each crater size and at each track density, the altimetry profiles of the craters were added to the altimetry profile of each background. The resulting synthetic altimetry tracks were used to generate synthetic DEMs using the same interpolation scheme as used on the real MOLA data. Example simulated crater fields $10 \mathrm{~km}$ in rim diameter are shown in Fig. 4, where the right half of each region also displays the track density. 


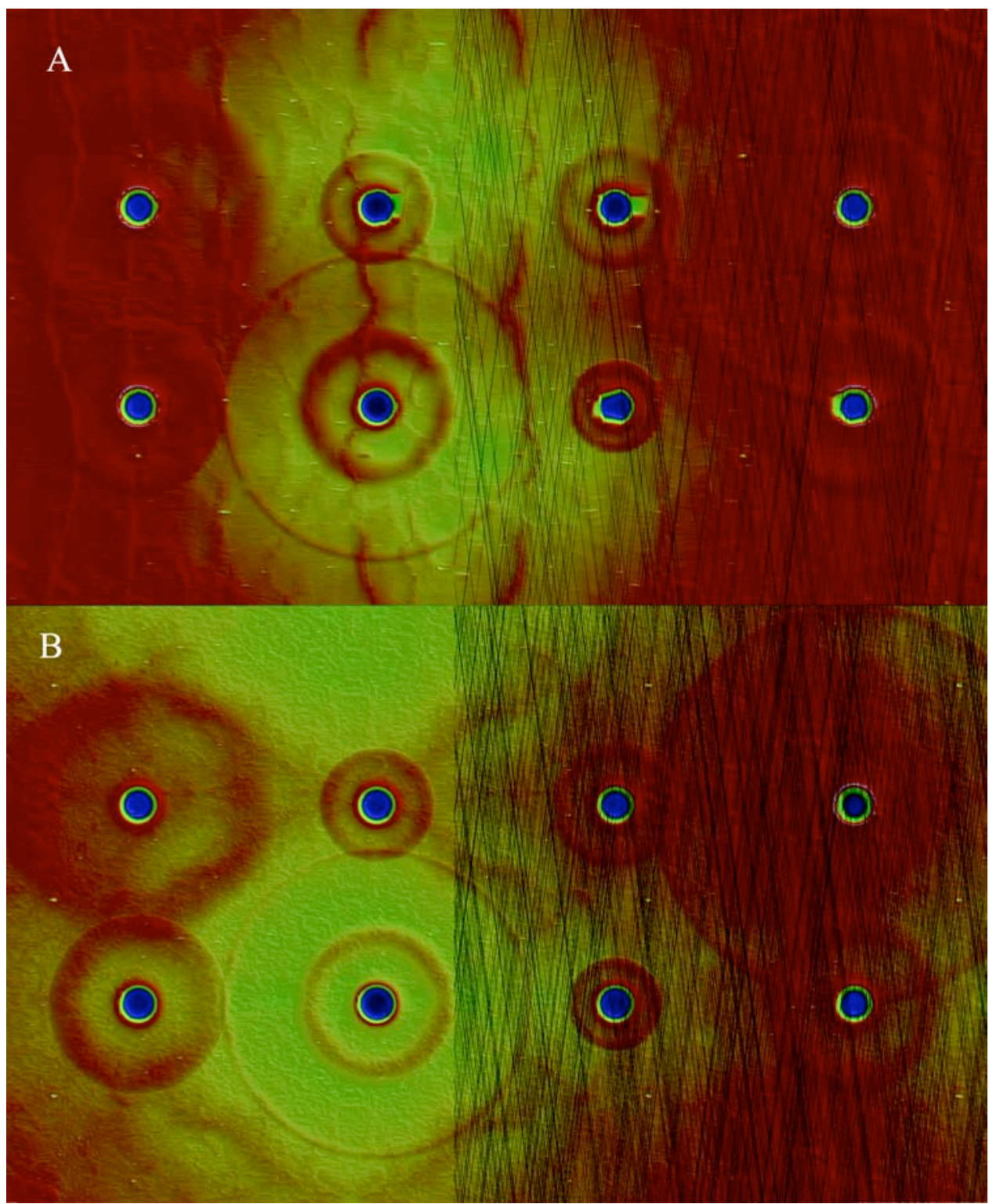

Fig. 4. Simulated craters $10 \mathrm{~km}$ in rim diameter on Martian background terrains. a) Lunae Planum with low track density, centered at $7^{\circ} \mathrm{N}$, $290^{\circ} \mathrm{E}$. b) Utopia Planitia with high track density, centered at $32^{\circ} \mathrm{N}, 98^{\circ} \mathrm{E}$. The footprint of each altimetry track overlies the right half of each image.

Identical measurements were performed on each background and at each track density at a DEM resolution of $0.3 \mathrm{~km} /$ pixel for $D_{\mathrm{R}} \geq 6 \mathrm{~km}$ and $0.15 \mathrm{~km} /$ pixel for $D_{\mathrm{R}} \leq 4 \mathrm{~km}$. When there were overlapping ejecta blankets, the pie-wedge tool was used to exclude these areas from the crater measurements. The results from error analyses of the simulated crater measurements are shown in Fig. 5.

The statistics presented in Fig. 5 demonstrate that the MOLA data resolves populations of craters with $D_{\mathrm{R}} \geq 6 \mathrm{~km}$ at all latitudes and at all track densities. Measurement accuracy begins to degrade when the number of points around the rim falls below about ten, although reasonable measurements are possible with as few as four rim points on $D_{\mathrm{R}}=4 \mathrm{~km}$ craters.
Large-scale topographic features in the background surface that cannot be interpolated accurately provide the greatest source of error on volume measurements of craters with $D_{\mathrm{R}}>$ $20 \mathrm{~km}$. At all sizes, the definition of the preimpact surface is the largest source of error in volume measurements.

For craters with $D_{\mathrm{R}} \geq 6 \mathrm{~km}$, the errors in measurement of the rim radius drop from $5 \%$ to less than $1 \%$ (Fig. $5 b$ ). For this measurement, the largest contribution to the rim radius error is the natural variability in the crater radius. On very smooth terrains, the error in the rim height is only a few percent (Figs. 5c and 5d), but on rough terrains, the error can be as large as $10-20 \%$. The rim depth of the crater has an error of only a few percent, except for large craters on rough terrains, 
where the error rises to $\sim 10 \%$ (Fig. 5e). The systematic errors in measurements of crater depth and rim height are dominated by the track coverage and the interpolation scheme to fit the rim crest along altimetry tracks. Because the systematic errors are relatively small, errors in real crater measurements are usually dominated by natural variability along the rim crest.

Crater cavity measurements are also very robust, with $\sim 10 \%$ error for $D_{\mathrm{R}} \geq 6 \mathrm{~km}$ across all terrains (Fig. $5 \mathrm{f}$ ). If crater infill is less than or comparable to $10 \%$, then cavity volume measurement errors are dominated by the interpolated DEM, and the effect of infill results in a negligible bias to the measurements. If crater infill is $>10 \%$, then the original cavity volume should be estimated by a model of the cavity profile immediately after the impact event.

The errors in the volume of ejecta plus uplifted surface, $V_{\text {Above }}$, are larger than $V_{\text {Cavity }}$ because of the larger area of interpolation for the preimpact surface (Fig. 5g). Nevertheless, on smooth surfaces, the systematic errors are only $\sim 20 \%$, rising to $\sim 60 \%$ on rougher surfaces. For simulated craters with known uplifted surface profiles, measurements of $V_{\text {Ejecta }}$ are only slightly worse than for $V_{\text {Above }}$ (Fig. 5h). Since the profile of the uplifted surface is not known for real craters, the uplifted surface subtraction remains the largest source of error for ejecta volume measurements.

We emphasize that the simulated crater analysis demonstrates that at all latitudes, populations of craters as small as $D_{\mathrm{R}}=2 \mathrm{~km}$ that are fresh and axisymmetric may be measured with typical errors $<30 \%$. There is almost no latitude dependence in the accuracy of crater population measurements using the MOLA data set for fresh craters with $D_{\mathrm{R}} \geq 2 \mathrm{~km}$. Hence, even though MOLA tracks rarely cross through the center of small craters, the general properties of a group of small craters can be measured coarsely. Errors in individual crater measurements are larger and harder to quantify. Confidence in individual crater measurements can be gauged by comparing measurements between different research groups who have developed their own measurement toolkits and strategies.

Hence, to further validate the HMars toolkit, we examined craters with published geometric measurements by Garvin et al. (2000) and Barnouin-Jha et al. (2005). Our measurements are in very good agreement with the published values, within the expected errors (Fig. 6). Note that rimdiameter measurements by Barnouin-Jha et al. (2005) are systematically larger than those of HMars, which has been confirmed by the authors (Barnouin-Jha, personal communication). The good agreement between individual crater geometry measurements by researchers using independent analytical tools suggests that high confidence may be placed in MOLA-based measurements of single fresh craters in the size range validated here $(\sim 5-12 \mathrm{~km}$ rim diameter).

Finally, we investigated the reproducibility of measurements of fresh craters by different users.
Comparisons between three different users yielded results within the expected errors. While individual crater measurements may vary by up to $\sim 2$ times the systematic $1 \sigma$ errors presented in Fig. 5, all data trends presented in this work are reproducible.

Therefore, we conclude that measurements of fresh impact craters using the HMars toolkit and the MOLA data set yields robust results. Furthermore, the systematic errors derived from analysis of simulated craters provide a means to discern the significance of observed differences in crater geometries between different terrains.

We propose that impact crater measurement techniques be validated using sets of simulated craters. The simulated craters used in this study are available from the authors. The crater sets are distributed as IDL "save" files, composed of simulated tracks (latitude, longitude) at three different track densities; simulated altitudes (for each crater size, track density, and background); and simulated crater DEMs on a flat background. The geometric parameters for each simulated crater are tabulated for comparison to measurements. The set of simulated fresh craters used in this study does not encompass all of the challenges encountered in crater measurements, e.g., degraded and severely nonaxisymmetric craters. We find that tailored simulated crater sets should be generated to gauge the accuracy of measurements of specific types of craters on representative background terrains for the goals of a particular investigation.

\section{CRATER MEASUREMENTS RESULTS}

\section{Study Regions and Definition of Fresh Craters}

We present the results from a survey of the freshest craters in Utopia Planitia-Elysium Mons region (U.P.), Isidis Planitia (I.P.), Acidalia Planitia (A.P.), Lunae Planum (L.P.), and Solis Planum (S.P.) (Fig. 7). The lowland surfaces and highland plateaus are relatively flat, so highly accurate geometrical measurements comparing highland and lowland surfaces are possible. A total of 501 potentially fresh craters were measured in these regions; heavily degraded craters were not measured. Craters at latitudes above $55^{\circ} \mathrm{N}$ were not considered because we observed significantly shallower crater depths in this population of craters. Craters were grouped by regions restricted to $86-150^{\circ} \mathrm{E}, 18-55^{\circ} \mathrm{N}$ for U.P., $81-100^{\circ} \mathrm{E}, 5-25^{\circ} \mathrm{N}$ for I.P., $308-355^{\circ} \mathrm{E}, 27-54^{\circ} \mathrm{N}$ for A.P., $286-300^{\circ} \mathrm{E}, 6-20^{\circ} \mathrm{N}$ for L.P., and $261-284^{\circ} \mathrm{E}, 15-30^{\circ} \mathrm{S}$ for S.P. In order to make more robust regional comparisons, craters in Isidis and Utopia were further restricted by the boundaries of the impact basins, shown in Fig. 7, centered at $87.4^{\circ} \mathrm{E}, 12.7^{\circ} \mathrm{N}$ and $112^{\circ} \mathrm{E}, 45^{\circ} \mathrm{N}$ with 1090 and $2100 \mathrm{~km}$ diameters, respectively (Frey et al. 1998; Thomson and Head 1999).

Fresh craters were identified quantitatively by deep crater 

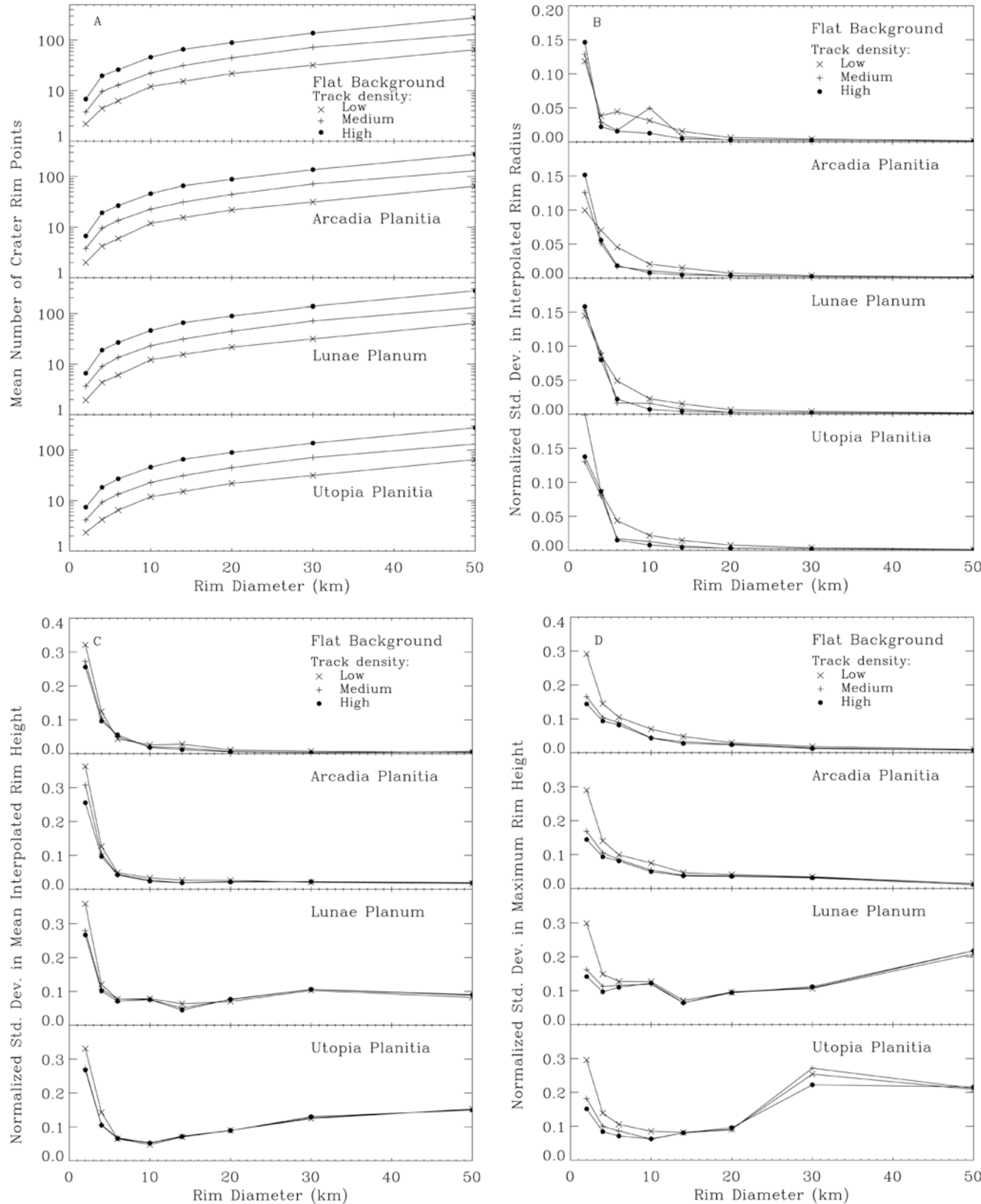

Fig. 5. Error analyses for HMars measurements of simulated crater data sets. a) Mean number of crater rim points. b) Normalized standard deviation $\left(1 \sigma_{\mathrm{m}} /\right.$ actual value) in interpolated rim radius. c) Normalized standard deviation in mean interpolated rim height. d) Normalized standard deviation in maximum rim height. 

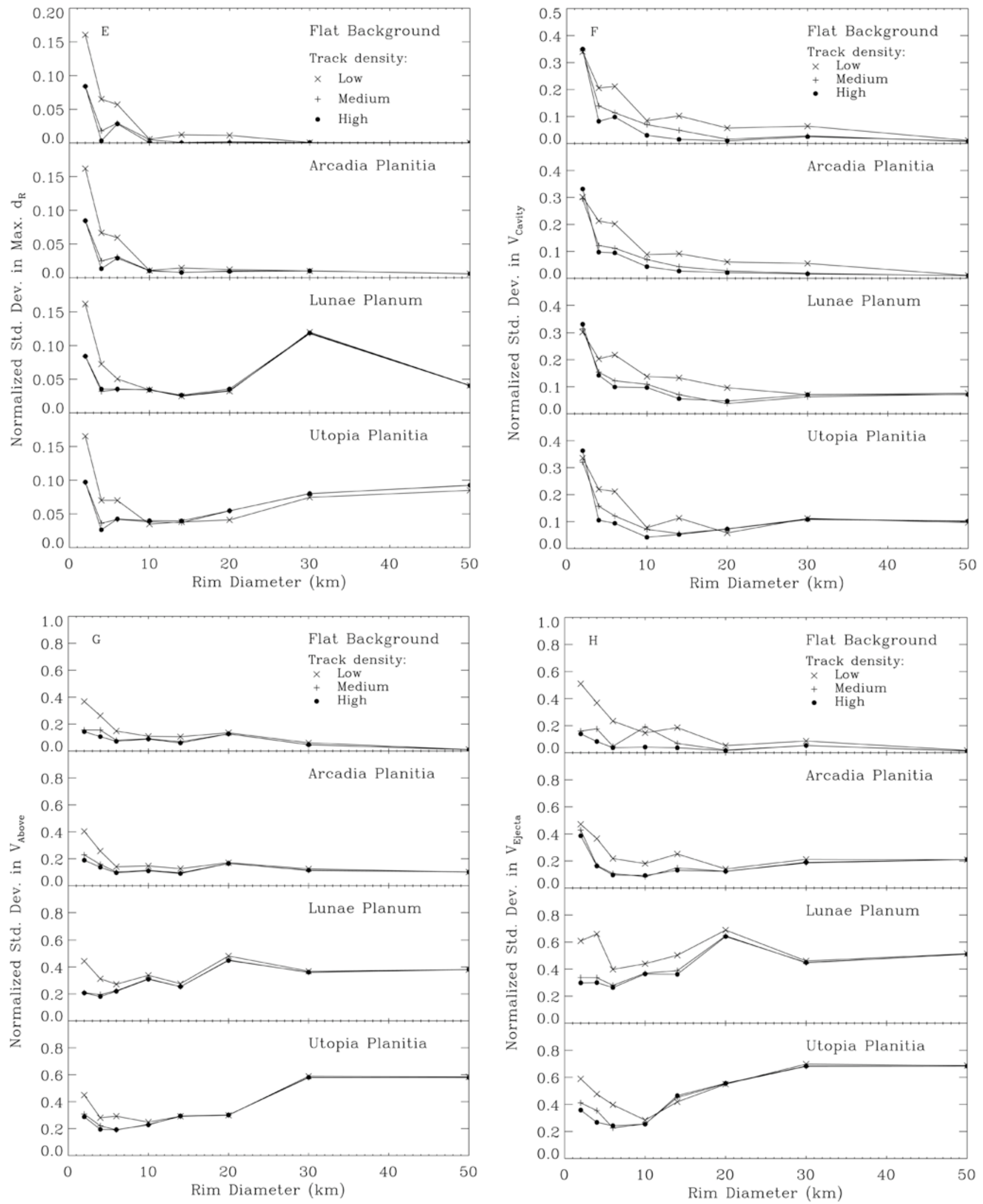

Fig. 5. Continued. Error analyses for HMars measurements of simulated crater data sets. e) Normalized standard deviation in maximum crater depth from rim. f) Normalized standard deviation in crater cavity volume. g) Normalized standard deviation in volume above background surface $\left(V_{\text {Uplift }}+V_{\text {Ejecta }}\right)$. h) Normalized standard deviation in volume of ejecta. 
Table 1. Power law fits to deepest crater depths, $d_{\mathrm{S}}$, and tallest crater rims, $H_{\mathrm{R}}$, in each region, with all variables in kilometers.

\begin{tabular}{llll}
\hline & $\begin{array}{l}\text { Strength regime } \\
\left(D_{\mathrm{S}}<10 \mathrm{~km}\right)\end{array}$ & $\begin{array}{l}\text { Gravity regime } \\
\left(D_{\mathrm{S}}>7 \mathrm{~km}\right)\end{array}$ & $\begin{array}{l}\text { Number of craters } \\
\text { (Equation } 1, c=0.65)\end{array}$ \\
\hline Acidalia Planitia & $F_{\mathrm{d}_{\mathrm{S}}}=0.276 D_{\mathrm{S}}^{0.782}$ & $F_{\mathrm{d}_{\mathrm{S}}}=0.579 D_{\mathrm{S}}^{0.276}$ & 29 \\
& $F_{\mathrm{H}_{\mathrm{R}}}=0.070 D_{\mathrm{S}}^{0.849}$ & $F_{\mathrm{H}_{\mathrm{R}}}=0.120 D_{\mathrm{S}}^{0.560}$ & \\
Utopia Planitia & $F_{\mathrm{d}_{\mathrm{S}}}=0.333 D_{\mathrm{S}}^{0.714}$ & $F_{\mathrm{d}_{\mathrm{S}}}=0.423 D_{\mathrm{S}}^{0.386}$ & 53 \\
Isidis Planitia & $F_{\mathrm{H}_{\mathrm{R}}}=0.115 D_{\mathrm{S}}^{0.569}$ & $F_{\mathrm{H}_{\mathrm{R}}}=0.165 D_{\mathrm{S}}^{0.483}$ & \\
& $F_{\mathrm{d}_{\mathrm{S}}}=0.342 D_{\mathrm{S}}^{0.744}$ & $F_{\mathrm{d}_{\mathrm{S}}}=0.503 D_{\mathrm{S}}^{0.305}$ & 24 \\
Lunae Planum & $F_{\mathrm{H}_{\mathrm{R}}}=0.063 D_{\mathrm{S}}^{0.874}$ & $F_{\mathrm{H}_{\mathrm{R}}}=0.234 D_{\mathrm{S}}^{0.409}$ & \\
& $F_{\mathrm{d}_{\mathrm{S}}}=0.197 D_{\mathrm{S}}^{0.667}$ & $F_{\mathrm{d}_{\mathrm{S}}}=0.395 D_{\mathrm{S}}^{0.347}$ & 48 \\
Solis Planum & $F_{\mathrm{H}_{\mathrm{R}}}=0.058 D_{\mathrm{S}}^{0.915}$ & $F_{\mathrm{H}_{\mathrm{R}}}=0.082 D_{\mathrm{S}}^{0.674}$ & \\
& $F_{\mathrm{d}_{\mathrm{S}}}=0.404 D_{\mathrm{S}}^{0.375}$ & $F_{\mathrm{d}_{\mathrm{S}}}=0.304 D_{\mathrm{S}}^{0.417}$ & 33 \\
& $F_{\mathrm{H}_{\mathrm{R}}}=0.046 D_{\mathrm{S}}^{1.045}$ & $F_{\mathrm{H}_{\mathrm{R}}}=0.153 D_{\mathrm{S}}^{0.337}$ & \\
\hline
\end{tabular}

cavities and high rims, and qualitatively by imagery of the crater and ejecta blanket. We focused on craters with $4<D_{\mathrm{R}}<$ $50 \mathrm{~km}$; however, in a few cases, smaller craters were well resolved and those were included in our analyses. We did not include larger craters $\left(D_{\mathrm{R}}>50 \mathrm{~km}\right)$ because these craters are systematically older, and thus more degraded, than the fresher, smaller craters.

Because all craters have experienced some level of degradation, we formulate criteria to identify the least degraded craters in each region. Since erosion softens the topography of impact craters, rim height and crater depth are strong indicators of preservation. To identify the least degraded craters in each region, we fit the maximum crater depth, $F_{\mathrm{d}_{\mathrm{s}}}$, and maximum rim height, $F_{\mathrm{H}_{\mathrm{R}}}$, as a function of diameter with two power laws, one for the strength regime and one for the gravity regime. The maximum value functions, which define the peak values for crater depth and rim height in each region, are given in Table 1. At each crater diameter, the best-preserved craters are defined by the following criteria:

$$
\begin{aligned}
& d_{\mathrm{S}}>c F_{\mathrm{d}_{\mathrm{s}}}\left[D_{\mathrm{S}},\right. \text { region], and } \\
& H_{\mathrm{R}}>c F_{\mathrm{H}_{\mathrm{R}}}\left[D_{\mathrm{S}},\right. \text { region], and } \\
& N_{\mathrm{R}} \geq 4
\end{aligned}
$$

$N_{\mathrm{R}}$ is the number of rim points. The number of rim points criterion, based on the results from the simulated crater analysis, establishes a minimum confidence level in the crater measurements. Since degradation and natural variability result in a continuum of values for rim height and crater depth, a cutoff point must be chosen to identify the freshest craters. Moderately fresh craters are defined by a cutoff value, $c$, of 0.4 and the freshest craters by a cutoff value of 0.65 . The cutoff values were chosen to identify a sufficient number of the least-degraded craters in each region for statistical analyses. The power law fits to the strength and gravity regimes overlap between $D_{\mathrm{S}}=7$ and $10 \mathrm{~km}$. In this transition region, a particular crater is included in a set with value $c$ when it satisfies the cutoff criteria in either regime. In Fig. 8, moderately fresh craters are plotted in black symbols and the 188 freshest craters are shown in colored symbols. Note that some moderately degraded craters with deep cavities do not have tall rims and vice-versa. The number of craters in each region identified by $c=0.65$ is given in Table 1 . The paraboloid crater shapes and comparisons to previously identified fresh crater populations on Earth, Mars, and the Moon (presented below) validate the approach taken here to identify fresh crater populations using the MOLA data.

\section{Results: Resolved Differences between Fresh Highland and Lowland Craters}

We find large, resolved differences between the freshest craters in the lowlands and highlands in their depth, rim height, cavity volumes, and volume above the preimpact surface. In Fig. 9a, the crater depth from the maximum rim point follows a continuous trend for the highland regions (triangle, diamond), but the lowland regions (circle, square, cross) have a break in the trend around the transition crater diameter, $7-10 \mathrm{~km}$. In this and all subsequent plots, the fit line color corresponds to the symbol color for each region and the power law fits are given in Table 2. The maximum $d_{\mathrm{R}}$ is significantly larger for strength-dominated craters in the lowlands compared to the highlands. A similar trend is 
Table 2. Crater geometry fits with $D_{\mathrm{R}}$ and $d_{\mathrm{S}}$ in kilometers.

\begin{tabular}{|c|c|c|c|c|}
\hline Region & Strength regime & Gravity regime & Strength regime & Gravity regime \\
\hline & \multicolumn{2}{|c|}{ Maximum $d_{\mathrm{R}}(\mathrm{km})($ Fig. 9) } & \multicolumn{2}{|c|}{$V_{\text {Above }}\left(\mathrm{km}^{3}\right)($ Fig. 14$)$} \\
\hline Acidalia Planitia & $d_{\mathrm{R}}=0.302 D_{\mathrm{R}}^{0.72}$ & $V_{\text {Cavity }}=0.126 D_{\mathrm{S}}^{2.56}$ & $V_{\text {Above }}=0.443 D_{\mathrm{S}}^{1.91}$ & $V_{\text {Above }}=0.175 D_{\mathrm{S}}^{2.44}$ \\
\hline Utopia Planitia & $d_{\mathrm{R}}=0.288 D_{\mathrm{R}}^{0.79}$ & $d_{\mathrm{R}}=0.738 D_{\mathrm{R}}^{0.29}$ & $V_{\text {Above }}=0.220 D_{\mathrm{S}}^{2.43}$ & $V_{\text {Above }}=0.207 D_{\mathrm{S}}^{2.44}$ \\
\hline Isidis Planitia & $d_{\mathrm{R}}=0.213 D_{\mathrm{R}}^{1.02}$ & $d_{\mathrm{R}}=0.494 D_{\mathrm{R}}^{0.43}$ & $V_{\text {Above }}=0.041 D_{\mathrm{S}}^{3.06}$ & $V_{\text {Above }}=0.296 D_{\mathrm{S}}^{2.23}$ \\
\hline Lunae Planum & $d_{\mathrm{R}}=0.261 D_{\mathrm{R}}^{0.59}$ & $d_{\mathrm{R}}=0.266 D_{\mathrm{R}}^{0.57}$ & $V_{\text {Above }}=0.015 D_{\mathrm{S}}^{3.54}$ & $V_{\text {Above }}=0.092 D_{\mathrm{S}}^{2.54}$ \\
\hline \multirow[t]{2}{*}{ Solis Planum } & $d_{\mathrm{R}}=0.532 D_{\mathrm{R}}^{0.26}$ & $d_{\mathrm{R}}=0.302 D_{\mathrm{R}}^{0.52}$ & $V_{\text {Above }}=0.167 D_{\mathrm{S}}^{2.13}$ & $V_{\text {Above }}=0.216 D_{\mathrm{S}}^{2.07}$ \\
\hline & \multicolumn{2}{|c|}{$d_{\mathrm{s}}(\mathrm{km})($ Fig. 10) } & \multicolumn{2}{|c|}{$V_{\text {Above }} / V_{\text {Cavity }}$ (Fig. 15) } \\
\hline Acidalia Planitia & $d_{\mathrm{S}}=0.425 D_{\mathrm{S}}^{0.38}$ & $d_{\mathrm{S}}=0.384 D_{\mathrm{S}}^{0.38}$ & \multicolumn{2}{|c|}{$V_{\text {Cavity }}=1.24 \pm 0.53$} \\
\hline Utopia Planitia & $d_{\mathrm{S}}=0.492 D_{\mathrm{S}}^{0.39}$ & $d_{\mathrm{S}}=0.404 D_{\mathrm{S}}^{0.41}$ & \multicolumn{2}{|c|}{$V_{\text {Cavity }}=1.48 \pm 0.88$} \\
\hline Isidis Planitia & $d_{\mathrm{S}}=0.691 D_{\mathrm{S}}^{0.27}$ & $d_{\mathrm{S}}=0.351 D_{\mathrm{S}}^{0.41}$ & \multicolumn{2}{|c|}{$V_{\text {Cavity }}=0.91 \pm 0.39$} \\
\hline Lunae Planum & $d_{\mathrm{S}}=0.238 D_{\mathrm{S}}^{0.47}$ & $d_{\mathrm{S}}=0.192 D_{\mathrm{S}}^{0.56}$ & \multicolumn{2}{|c|}{$V_{\text {Cavity }}=1.07 \pm 0.43$} \\
\hline Solis Planum & $d_{\mathrm{S}}=0.469 D_{\mathrm{S}}^{0.16}$ & $d_{\mathrm{S}}=0.175 D_{\mathrm{S}}^{0.62}$ & \multicolumn{2}{|c|}{$V_{\text {Cavity }}=0.83 \pm 0.34$} \\
\hline & \multicolumn{2}{|c|}{$H_{\mathrm{R}}(\mathrm{km})($ Fig. 12) } & \multicolumn{2}{|c|}{$D_{\mathrm{R}} / D_{\mathrm{S}}($ Fig. 17$)$} \\
\hline Acidalia Planitia & $H_{\mathrm{R}}=0.082 D_{\mathrm{R}}^{0.54}$ & $H_{\mathrm{R}}=0.072 D_{\mathrm{R}}^{0.62}$ & $D_{\mathrm{R}} D_{\mathrm{S}}=1.28 D_{\mathrm{R}}^{-0.070}$ & $D_{\mathrm{R}} D_{\mathrm{S}}=1.09 D_{\mathrm{R}}^{0.013}$ \\
\hline Utopia Planitia & $H_{\mathrm{R}}=0.076 D_{\mathrm{R}}^{0.70}$ & $H_{\mathrm{R}}=0.175 D_{\mathrm{R}}^{0.33}$ & $D_{\mathrm{R}} D_{\mathrm{S}}=1.47 D_{\mathrm{R}}^{-0.107}$ & $D_{\mathrm{R}} D_{\mathrm{S}}=1.18 D_{\mathrm{R}}^{-0.014}$ \\
\hline Isidis Planitia & $H_{\mathrm{R}}=0.036 D_{\mathrm{R}}^{1.03}$ & $H_{\mathrm{R}}=0.133 D_{\mathrm{R}}^{0.51}$ & $D_{\mathrm{R}} D_{\mathrm{S}}=1.29 D_{\mathrm{R}}^{-0.047}$ & $D_{\mathrm{R}} D_{\mathrm{S}}=1.18 D_{\mathrm{R}}^{-0.016}$ \\
\hline Lunae Planum & $H_{\mathrm{R}}=0.081 D_{\mathrm{R}}^{0.57}$ & $H_{\mathrm{R}}=0.091 D_{\mathrm{R}}^{0.47}$ & $D_{\mathrm{R}} D_{\mathrm{S}}=1.18 D_{\mathrm{R}}^{-0.025}$ & $D_{\mathrm{R}} D_{\mathrm{S}}=1.14 D_{\mathrm{R}}^{-0.012}$ \\
\hline \multirow[t]{2}{*}{ Solis Planum } & $H_{\mathrm{R}}=0.065 D_{\mathrm{R}}^{0.75}$ & $H_{\mathrm{R}}=0.138 D_{\mathrm{R}}^{0.23}$ & $D_{\mathrm{R}} D_{\mathrm{S}}=1.28 D_{\mathrm{R}}^{-0.070}$ & $D_{\mathrm{R}} D_{\mathrm{S}}=1.08 D_{\mathrm{R}}^{0.011}$ \\
\hline & \multicolumn{2}{|c|}{$V_{\text {Cavity }}\left(\mathrm{km}^{3}\right)($ Fig. 13$)$} & \multicolumn{2}{|c|}{$V_{\text {Ejecta }}\left(\mathrm{km}^{3}\right)($ Fig. 21$)$} \\
\hline Acidalia Planitia & $V_{\text {Cavity }}=0.126 D_{\mathrm{S}}^{2.56}$ & $V_{\text {Cavity }}=0.152 D_{\mathrm{S}}^{2.43}$ & $V_{\text {Ejecta }}=0.593 D_{\mathrm{R}}^{1.40}$ & $V_{\text {Ejecta }}=0.102 D_{\mathrm{R}}^{2.37}$ \\
\hline Utopia Planitia & $V_{\text {Cavity }}=0.132 D_{\mathrm{S}}^{2.59}$ & $V_{\text {Cavity }}=0.288 D_{\mathrm{S}}^{2.20}$ & $V_{\text {Ejecta }}=0.644 D_{\mathrm{R}}^{1.36}$ & $V_{\text {Ejecta }}=0.102 D_{\mathrm{R}}^{2.46}$ \\
\hline Isidis Planitia & $V_{\text {Cavity }}=0.258 D_{\mathrm{S}}^{2.24}$ & $V_{\text {Cavity }}=0.161 D_{\mathrm{S}}^{2.39}$ & $V_{\text {Ejecta }}=0.004 D_{\mathrm{R}}^{3.71}$ & $V_{\text {Ejecta }}=0.080 D_{\mathrm{R}}^{2.41}$ \\
\hline Lunae Planum & $V_{\text {Cavity }}=0.077 D_{\mathrm{S}}^{2.64}$ & $V_{\text {Cavity }}=0.098 D_{\mathrm{S}}^{2.52}$ & $V_{\text {Ejecta }}=0.001 D_{\mathrm{R}}^{4.49}$ & $V_{\text {Ejecta }}=0.052 D_{\mathrm{R}}^{2.49}$ \\
\hline Solis Planum & $V_{\text {Cavity }}=0.178 D_{\mathrm{S}}^{2.20}$ & $V_{\text {Cavity }}=0.072 D_{\mathrm{S}}^{2.66}$ & $V_{\text {Ejecta }}=0.023 D_{\mathrm{R}}^{2.82}$ & $V_{\text {Ejecta }}=0.082 D_{\mathrm{R}}^{2.05}$ \\
\hline
\end{tabular}

observed for the average value of $d_{\mathrm{R}}$. The trends for crater rim depths reported by Garvin et al. (2003) and Pike (1980) are in good agreement with the highland craters (Fig. 9b). The power law fits in all regions converge as crater diameter increases. For $D_{\mathrm{R}} \sim 8 \mathrm{~km}$, the lowland crater depths are factors of 1.5 to 2.0 times greater than crater depths in Lunae Planum and Solis Planum (Fig. 9c). Lunae Planum is used as a reference in Fig. 9 and subsequent figures to illustrate the differences between fits to the data, because the population of craters in this region exhibits the least scatter of the regions studied here.

In all figures of crater measurements versus diameter, the reader should refer to the simulated crater analyses presented in Fig. 5 to estimate the magnitude of the measurement error, which varies a function of crater diameter and terrain. The systematic measurement error, $\sigma_{\mathrm{m}}$, for crater depth has a normalized standard deviation of $<5 \%$ in this size range (Fig. 5e), so the observations are $\geq 10 \sigma_{\mathrm{m}}$ above the measurement error. However, the dominant error is the observed natural variability in each crater population. The standard deviation in the rim height measurement around a single crater is on average about $15 \%$, which contributes to about a $4 \%$ error on the rim depth (which corresponds to about 1-2 symbol radii in Fig. 9). The observed measurement scatter of rim depth around the fit in each region, $\sigma_{0}$, varies from $4.5 \%$ in Isidis to $10 \%$ in Solis Planum, so the observed regional differences are $\geq 5 \sigma_{0}$ detections.

Most of the difference in crater rim depths, $d_{\mathrm{R}}=d_{\mathrm{S}}+H_{\mathrm{R}}$, 

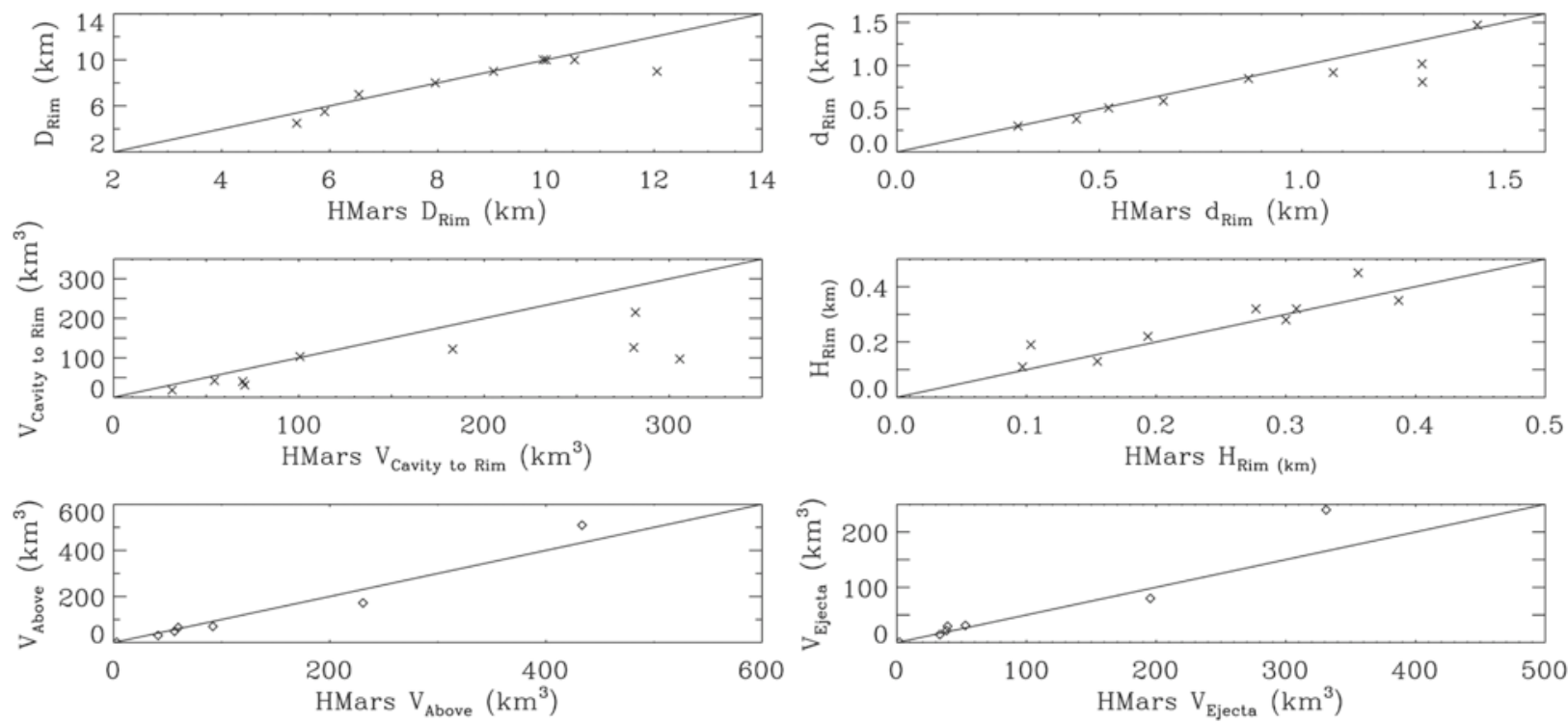

Fig. 6. Comparisons of crater geometry measurements from HMars (horizontal axis) to published values from Garvin et al. (2000) (X's) and Barnouin-Jha et al. (2005) (diamonds) (vertical axis). Solid line is one-to-one correspondence.

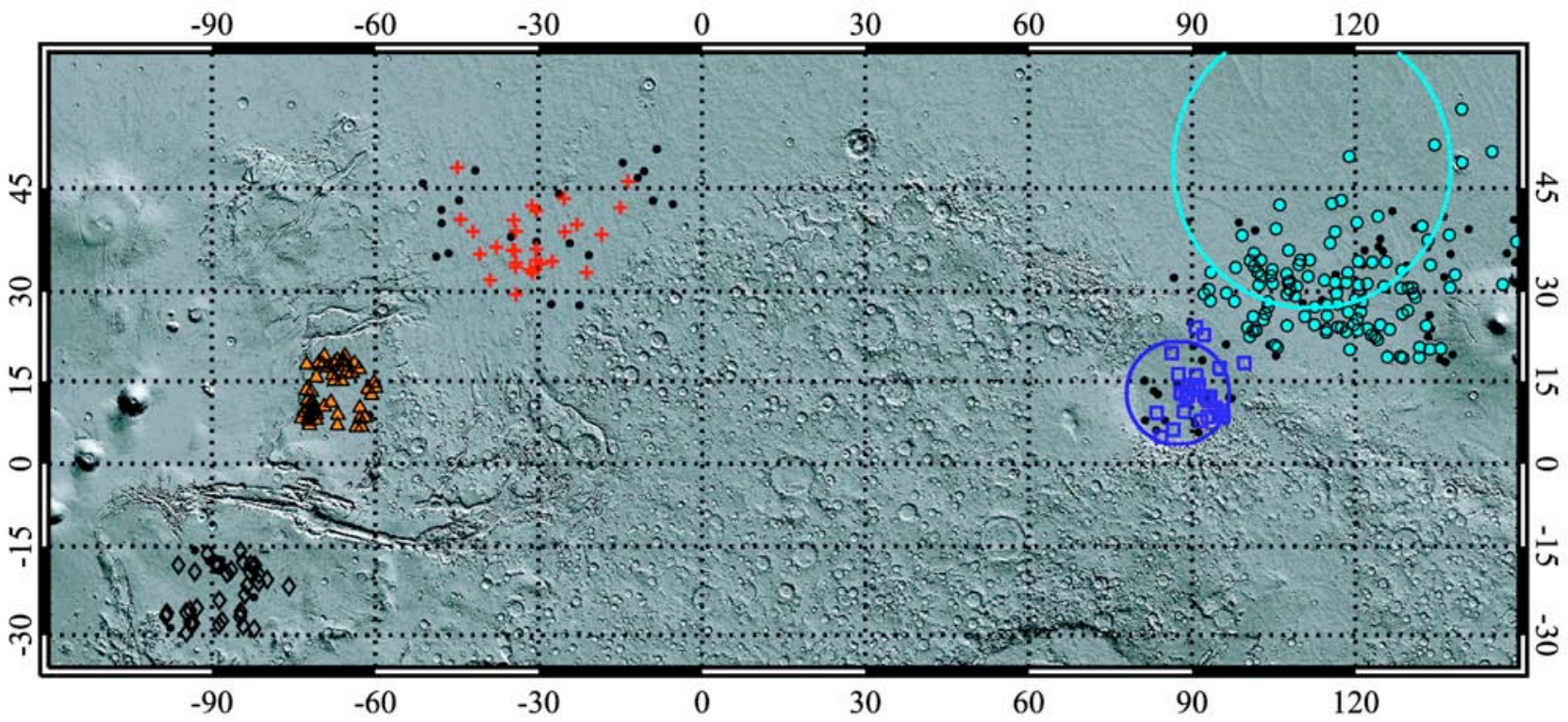

Fig. 7. Freshest well-resolved craters with diameters $\geq 4 \mathrm{~km}$ in Utopia-Elysium region = circles, Isidis impact basin $=$ squares, Acidalia Planitia $=$ crosses, Lunae Planum = triangles, and Solis Planum = diamonds. Filled black dots denote moderately fresh craters. The background is shaded MOLA topography in Mercator projection.

is found in the depth from the preimpact surface level, $d_{\mathrm{S}}$ (refer to Fig. 2). In Fig. 10, the surface depths follow the same general trend as the rim depths, but in this case, the difference between highlands and lowlands become more pronounced as the crater diameter decreases. As shown in Fig. 8, the maximum rim uplift heights are more tightly clustered than the surface depths for fresh craters. The difference in crater shape is apparent in typical MOLA track profiles for fresh craters $\sim 9 \mathrm{~km}$ in rim diameter in each region (Fig. 11). The natural variation in the background surface elevation around the crater contributes $2 \%$ to the error in the surface depth, or about 1 symbol radius in Fig. 10.

Although the rim height variations are smaller than crater depth variations, there are a couple of general trends. In the strength regime, the rim heights are similar in each region (Fig. 12a). For all crater sizes, the rim heights for the freshest craters in this study are similar to measurements of fresh lunar craters (Pike 1977) but systematically taller than globally averaged values for fresh Martian craters from Garvin et al. (2003) (Fig. 12b). Simple lunar craters display a nearly 


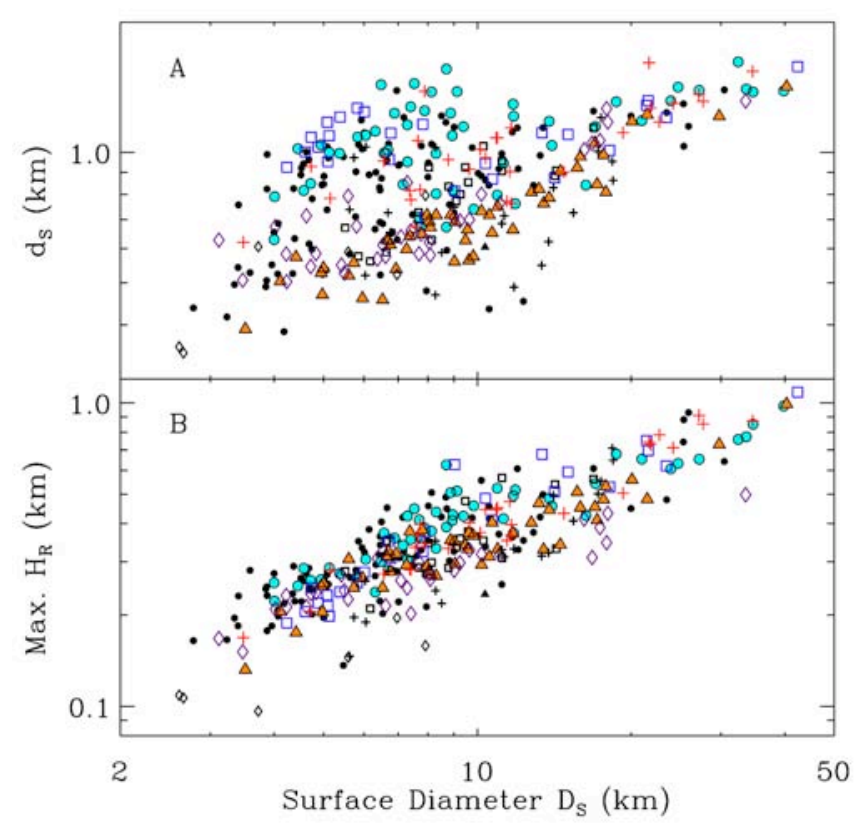

Fig. 8.The freshest craters (colored symbols) are defined by having both (a) deep crater cavities and (b) tall rim heights (Equation 1 with $c=0.65$. Utopia basin $=$ circles; Isidis basin $=$ squares; Acidalia Planitia = crosses; Lunae Planum = triangles; Solis Planum = diamonds. Smaller black symbols denote moderately fresh craters in each region $(c=0.4)$.

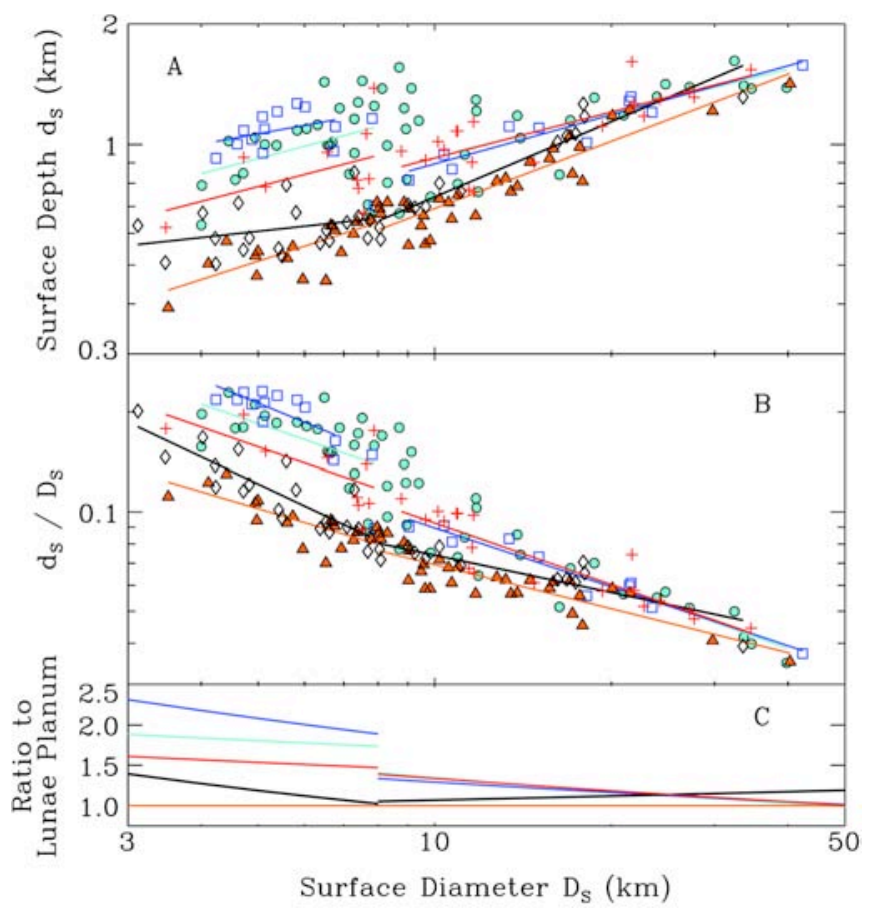

Fig. 10. The depth of the crater from average preimpact surface elevation. a) Power law fits to freshest craters in each region. b) Power law fits to ratio of surface depth to surface diameter. c) Ratio of power law fits in (a) to Lunae Planum fit. Utopia basin = circles; Isidis basin = squares; Acidalia Planitia = crosses; Lunae Planum = triangles; Solis Planum = diamonds.

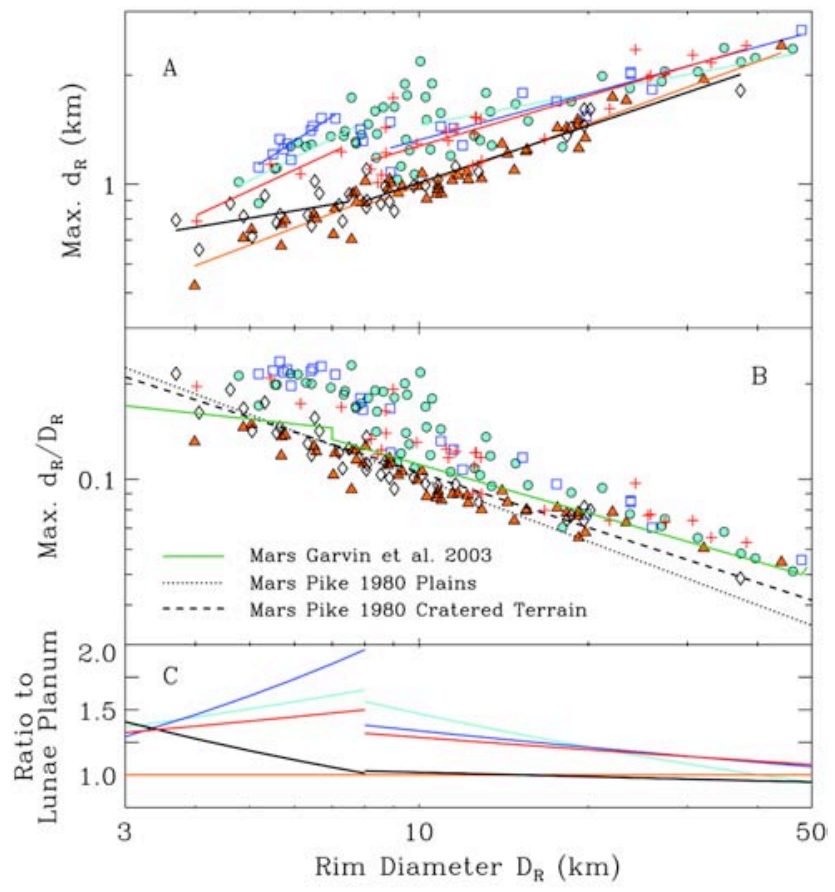

Fig. 9. The depth of the crater from maximum rim point. a) Power law fits to freshest craters in each region. Fit-line colors correspond to the color of symbols in each region. b) A comparison of rim depthto-rim diameter ratio to previously published crater depth functions. c) The ratio of power law fits in (a) to Lunae Planum fit. Utopia basin = circles; Isidis basin = squares; Acidalia Planitia = crosses; Lunae Planum $=$ triangles; Solis Planum $=$ diamonds .

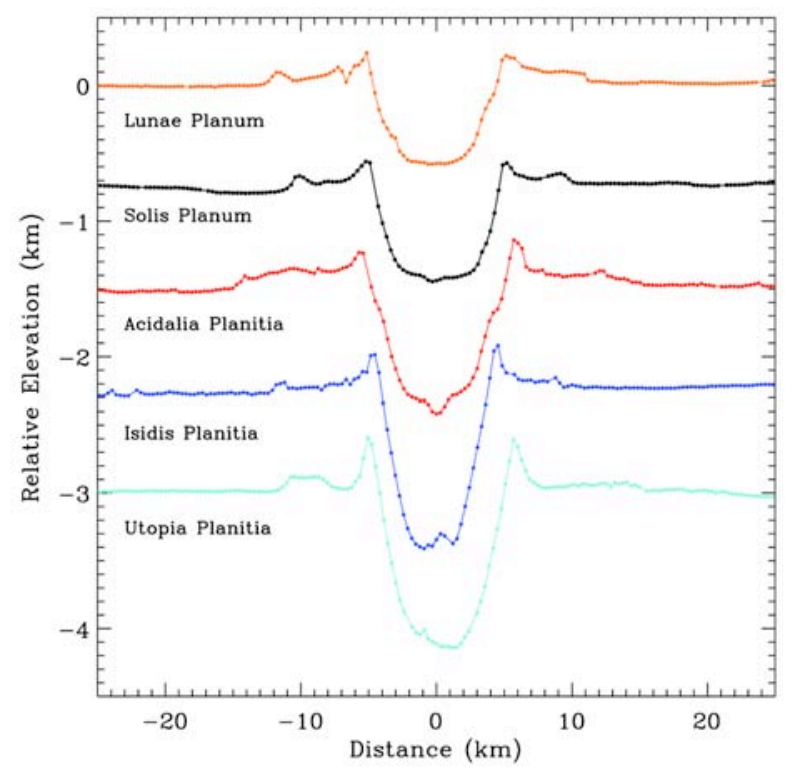

Fig. 11. Typical MOLA altimetry profiles passing near the center of fresh craters $\left(D^{\mathrm{R}} \sim 9 \mathrm{~km}\right)$. Each dot represents an individual MOLA measurement. Crater locations: L.P. $\left(293.0^{\circ} \mathrm{E}, 18.6^{\circ} \mathrm{N}\right)$; S.P. $\left(277.0^{\circ} \mathrm{E}, 19.5^{\circ} \mathrm{S}\right)$; A.P. $\left(325.8^{\circ} \mathrm{E}, 39.1^{\circ} \mathrm{N}\right)$; I.P. $\left(88.0^{\circ} \mathrm{E}, 12.8^{\circ} \mathrm{N}\right)$; U.P. $\left(109.6^{\circ} \mathrm{E}, 34.2^{\circ} \mathrm{N}\right)$. The vertical exaggeration is $10: 1$. The sharp dip in the profile near the Lunae Planum crater rim is a small crater which formed on the ejecta blanket. 
constant rim height to diameter ratio, $H_{\mathrm{R}} / D_{\mathrm{R}}$, of 0.036 . The lunar complex crater $H_{\mathrm{R}} / D_{\mathrm{R}}$ power law is corrected for the difference in gravity between the two bodies by a factor of $g_{\text {Moon }} / g_{\text {Mars }}$. Our measurement of rim heights interpolates the altimetry profiles to fit for the rim crest, and the excellent correlation to lunar crater profiles lends support to this approach. The rim height measurements by Garvin et al. (2003) may be biased by regions with shallower rim heights in the global average and/or a different approach to measurement of the rim crest. In the gravity regime, the mean interpolated rim heights of lowland craters are slightly larger than highland craters, where the power law fits differ by factors of 0.25 to 0.75 (Fig. 12c). The toolkit measurement errors of rim height are typically $10 \%$ or less (Fig. $5 \mathrm{c}$ ). The observed mean normalized standard deviation of crater rim heights is $17 \%$, averaging over all regions, so the measurement errors are dominated by the natural variability around the crater rim (Fig. 12d). While the differences are not dramatic, there is a robust trend for taller rim heights in the lowland, gravity-dominated, freshest craters.

Significant differences are observed in crater cavity volume, as expected from the variations in crater depth. Gravity-dominated craters in each region have similar cavity volumes, but lowland strength-dominated craters have significantly larger cavity volumes compared to highland craters of the same crater diameter (Fig. 13). Lowland craters with $D_{\mathrm{S}} \leq 10 \mathrm{~km}$ have volumes $>50 \%$ larger than highland craters. Typical measurement errors of $V_{\text {Cavity }}$ are $\sim 10 \%$ (Fig. 5f); hence, the volume measurements are well resolved $\left(\geq 5 \sigma_{\mathrm{m}}\right)$. The observed scatter around the power law fits vary from 20 to $30 \%$, so the volume differences are resolved by $\geq 2 \sigma_{0}$. The volume of the crater cavity measured from the peak rim height, $V_{\text {Rim }}$, shows the same trend as $V_{\text {Cavity. }}$

The combined volume of ejecta and uplifted preimpact surface, $V_{\text {Above }}$, is systematically larger in the lowlands for all crater sizes, with the exception of small craters in Isidis. $V_{\text {Above }}$ is $50-100 \%$ larger for lowland craters (Fig. 14). The measurement error for $V_{\text {Above }}$ ranges between 20 and $60 \%$ (Fig. 5g). The volume difference is best resolved for crater diameters between 6 and $20 \mathrm{~km}$. By mass conservation and neglecting the effects of bulking, the volume of the crater cavity below the preimpact surface is approximately equal to the combined volume of uplifted and ejected material (Fig. 15). As expected, the average values for the ratio, $V_{\text {Above }} /$ $V_{\text {Cavity, }}$ are nearly 1 . Notably, there is a population of craters with an excess of material above the preimpact surface. Ratios greater than 2 are more than $2 \sigma$ away from the average for all craters excluding Utopia. There is a slight size dependence in the $V_{\text {Above }} / V_{\text {Cavity }}$ ratio for craters in S.P. and I.P., but the other regions have a nearly constant average value for all crater sizes. The relative contributions to $V_{\mathrm{Above}}$ from $V_{\text {Uplift }}$ and $V_{\text {Ejecta }}$ are discussed in the "Ejecta Volumes and the Z-EDOZ Model" section.

To verify that the data set of freshest craters does not have anomalously shaped craters, the depth from the surface is compared to ideal values for a paraboloid with the measured surface diameter and cavity volume (Fig. 16). All of the freshest craters have nearly paraboloid cavity shapes. Note that the highland craters are systematically slightly shallower than the lowland craters. Another useful shape parameter is the ratio of the rim diameter to the surface diameter, $D_{\mathrm{R}} / D_{\mathrm{S}}$, shown in Fig. 17 , which will be used in the "Comparison to Observations and Improving the Scaling Relationships" section. Gravity regime craters all display similar values of $D_{\mathrm{R}} / D_{\mathrm{S}} \sim 1.12$. Strength-dominated craters in the Isidis and Utopia basins have slightly larger values of $D_{\mathrm{R}} /$ $D_{\mathrm{S}}$, indicating that the upper crater walls are less steep compared to the other regions.

In summary, we find large, resolved differences between the freshest highland and lowland craters. The observed differences are larger than the natural variability in crater shapes and larger than measurement error limits using the MOLA data. There are significant differences in the crater depth $\left(\geq 5 \sigma_{0}\right)$ and cavity volumes $\left(\geq 2 \sigma_{0}\right)$ for strengthdominated craters. Rim heights and $V_{\text {Above }}$ are slightly larger in the lowlands for all crater sizes. There is a population of craters in Utopia with excess $V_{\text {Above }}$ compared to $V_{\text {Cavity, }}$ which is discussed in more detail by Black and Stewart (Forthcoming). All fresh crater cavities have paraboloid shapes. The observed values for $D_{\mathrm{R}} / D_{\mathrm{S}}$ are slightly lower than the typical value of 1.3 used in crater scaling (Melosh 1989, 1998). The larger $d_{\mathrm{R}} / D_{\mathrm{R}}$ values for simple lowland craters compared to simple highland craters suggest that the surface materials have different effective strengths, which is discussed in the next section.

\section{IMPLICATIONS FOR MARTIAN SUBSURFACE PROPERTIES}

The definition of the freshest craters in this study identifies the least degraded and preferentially youngest craters in each region. Here we make the reasonable assumption that the freshest craters in each region were formed by the same impactor population. The freshest lowland craters are Amazonian and the freshest highland craters likely formed in the same epoch. Therefore, systematic differences in the observed crater population should reflect differences in the properties of the target surfaces.

\section{Crater Scaling Relationships}

The difference in surface properties may be quantified through the use of cratering scaling relationships, such as the commonly used $\pi$-group scaling laws (Melosh 1989). In this section, we derive the crater diameter and volume as a function of the impact parameters and the effective surface strength. These relationships are used in the next section to investigate the difference in surface strength between regions on Mars. 


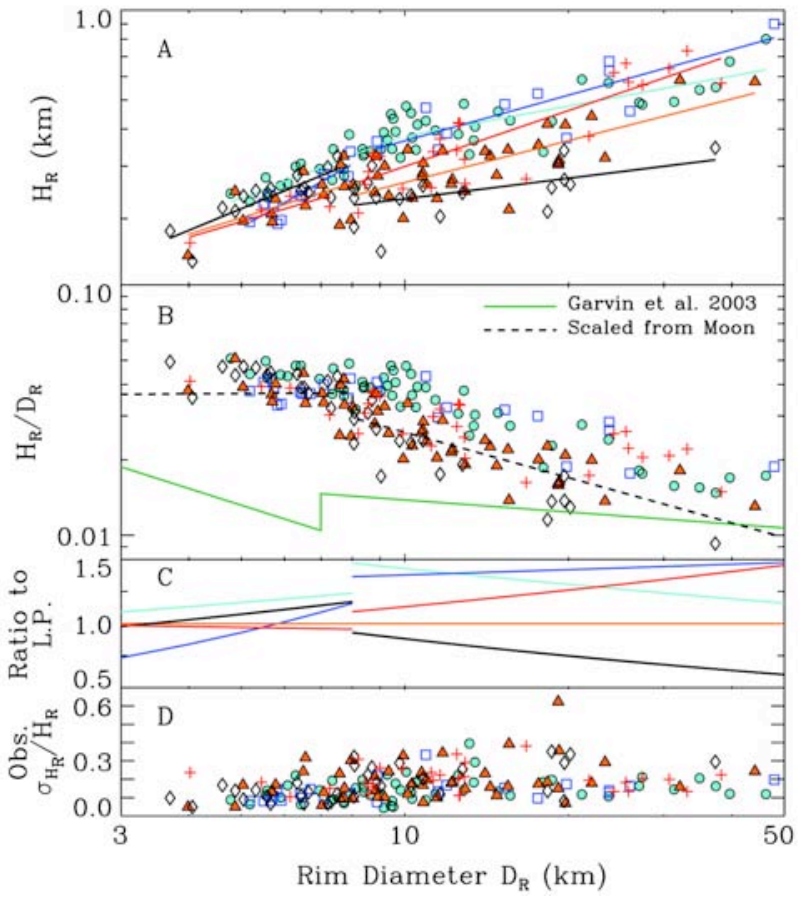

Fig. 12. Mean interpolated rim heights. a) Power law fits to freshest craters in each region. b) Comparison to published Martian global rim height functions and lunar craters (Pike 1977). c) Ratio of power law fits in (a) to Lunae Planum fit. d) Normalized standard deviation of rim point measurements. Utopia basin = circles; Isidis basin = squares; Acidalia Planitia = crosses; Lunae Planum = triangles; Solis Planum $=$ diamonds.

Nondimensional scaling parameters, crater diameters, and volumes are defined by:

$$
\begin{gathered}
\pi_{2}=\frac{1.61 g D_{\mathrm{P}}}{v_{\mathrm{i}}^{2}} \\
\pi_{3}=\frac{Y}{\rho v_{\mathrm{i}}^{2}} \\
\pi_{\mathrm{D}}=D_{\mathrm{ST}}\left(\frac{\rho}{m_{\mathrm{P}}}\right)^{1 / 3} \\
\pi_{\mathrm{V}}=V_{\mathrm{T}} \frac{\rho}{m_{\mathrm{P}}}
\end{gathered}
$$

where $\pi_{2}$ is the inverse Froude number, $\pi_{3}$ is the inverse Cauchy number, $D_{\mathrm{P}}$ is the projectile diameter, $g=3.72 \mathrm{~m} \mathrm{~s}^{-2}$ is the gravitational acceleration on Mars, and $v_{\mathrm{i}}=10 \mathrm{~km} \mathrm{~s}^{-1}$ is the average asteroid impact velocity on Mars (Bottke et al. 1994). The density of the projectile and surface are assumed to be equal with $\rho=2800 \mathrm{~kg} \mathrm{~m}^{-3}$, and $m_{\mathrm{P}}$ is the mass of the projectile. $V_{\mathrm{T}}$ is the volume of the transient cavity below the preimpact surface, $D_{\mathrm{ST}}$ is the diameter of the transient cavity at the preimpact surface, and $Y$ is the effective strength of the surface.

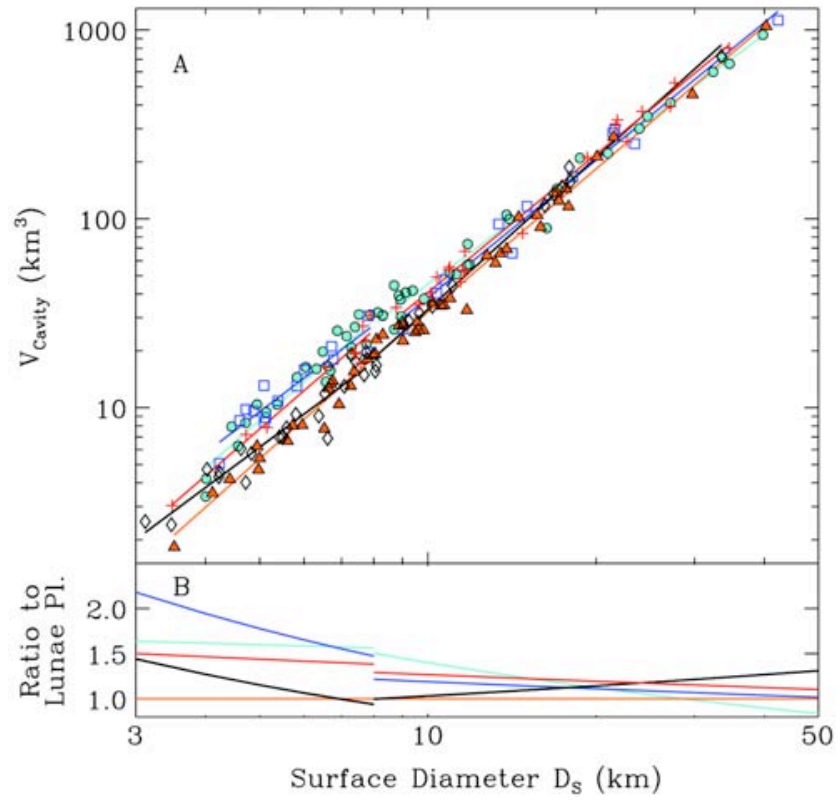

Fig. 13. Cavity volume below preimpact surface. a) Power law fits to freshest craters in each region. b) Ratio of power law fits in (a) to Lunae Planum fit. Utopia basin = circles; Isidis basin = squares; Acidalia Planitia = crosses; Lunae Planum = triangles; Solis Planum $=$ diamonds.

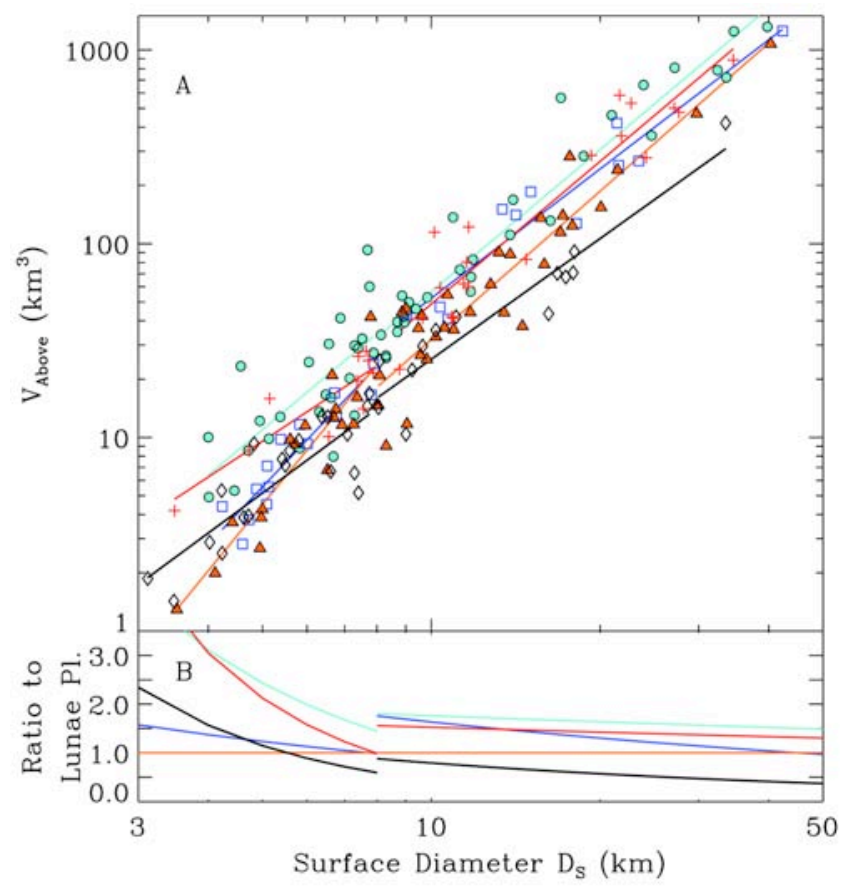

Fig. 14. The volume above the preimpact surface (combined ejecta and uplifted surface volume). a) Power law fits to freshest craters in each region. b) The ratio of power law fits in (a) to Lunae Planum fit. Utopia basin = circles; Isidis basin = squares; Acidalia Planitia $=$ crosses; Lunae Planum $=$ triangles; Solis Planum = diamonds. 


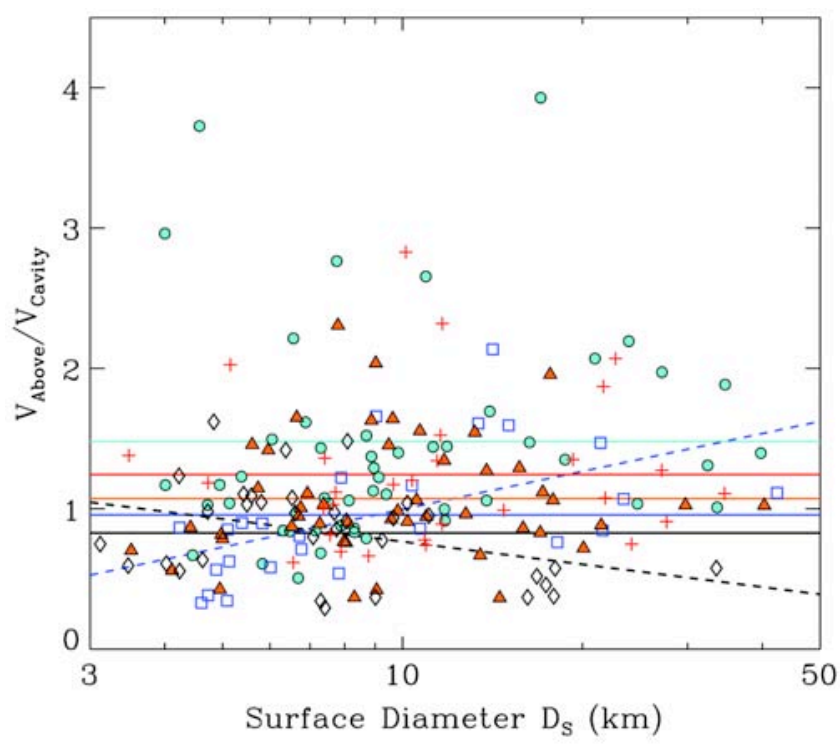

Fig. 15. The ratio of volume above preimpact surface to cavity volume with mean values (solid lines) and log-linear fits to U.P. and S.P. (dashed lines). Utopia basin = circles; Isidis basin = squares; Acidalia Planitia = crosses; Lunae Planum = triangles; Solis Planum = diamonds.

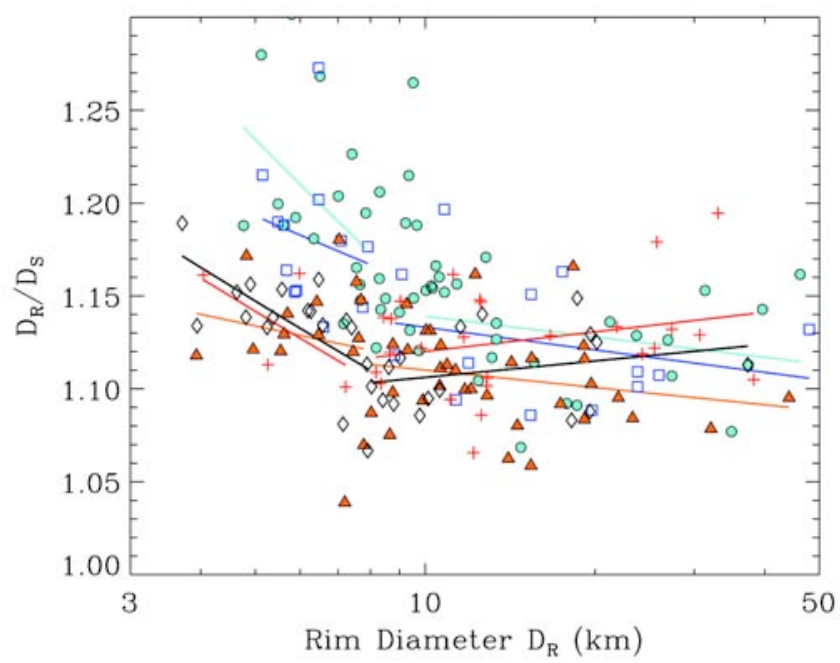

Fig. 17. The ratio of rim diameter-to-surface diameter for freshest craters with power law fits. Utopia basin = circles; Isidis basin = squares; Acidalia Planitia = crosses; Lunae Planum = triangles; Solis Planum $=$ diamonds.

First we present the formulae for the transient and final crater diameter using the gravity scaling parameter $\pi_{2}$. In the gravity regime, the surface diameter of the transient cavity scales as:

$$
\pi_{\mathrm{D}}=C_{2} \pi_{2}^{-\beta}
$$

where $C_{2}=1.6$ and $\beta=0.22$ for competent rock (Schmidt and Housen 1987). The scaled transient crater surface diameter

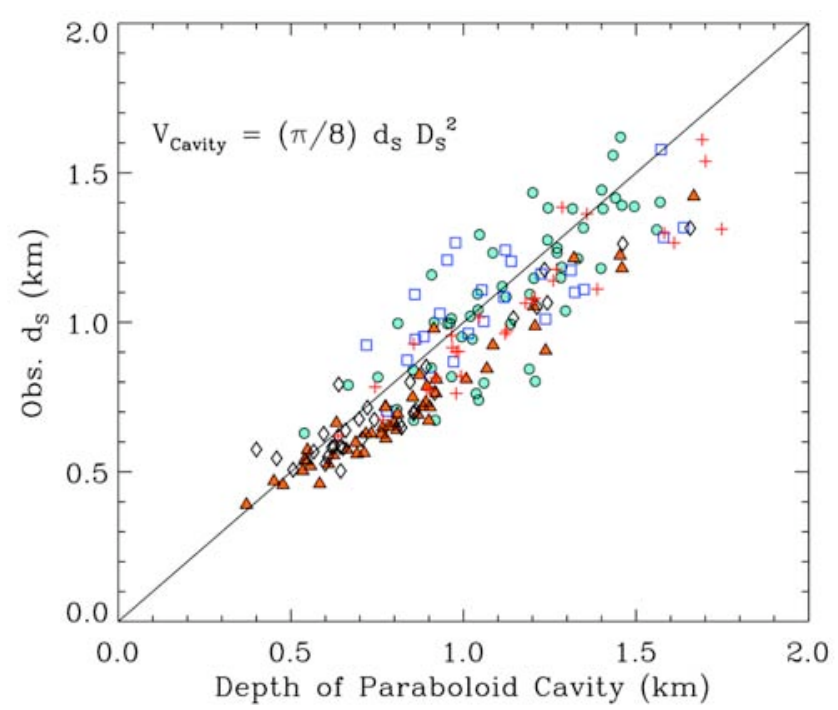

Fig. 16. The depth from the surface, $d_{\mathrm{S}}$, of the freshest crater cavities compared to expected depth for paraboloid cavity with observed volume, $V_{\text {Cavity }}$, and surface diameter, $D_{\mathrm{S}}$. Solid line is a one-to-one correlation. Utopia basin = circles; Isidis basin = squares; Acidalia Planitia $=$ crosses; Lunae Planum = triangles; Solis Planum = diamonds.

has an adjustment for the impact angle from the surface, $\phi$, which is 45 degrees on average:

$$
D_{\mathrm{ST}}=C_{2} \pi_{2}^{-\beta}\left(\frac{\rho}{m}\right)^{-1 / 3}(\sin \phi)^{-1 / 3}
$$

Following the method of Melosh (1998), transient craters in the strength regime may be approximated by the $\pi_{2}$ gravity scaling law. The final rim diameter separating the strength and gravity regimes may be scaled from the observed lunar

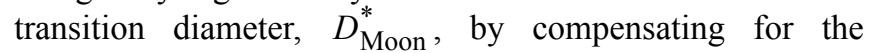
differences in gravity and density of the surface: $D_{\text {Mars }}^{*}=D_{\text {Moon }}^{*}\left[(\rho g)_{\text {Moon }} /(\rho g)_{\text {Mars }}\right]$. Using $\rho_{\text {Moon }}=$ $2700 \mathrm{~kg} \mathrm{~m}^{-3}, g_{\text {Moon }}=1.67 \mathrm{~m} \mathrm{~s}^{-2}$, and $D_{\text {Moon }}^{*}=18.7 \mathrm{~km}$, $D_{\text {Mars }}^{*}=8.1 \mathrm{~km}$. During the final stage of crater formation, simple craters widen by crater wall slumping by a factor of $C_{\mathrm{D}}$ $=1.2$ (e.g., $D_{\mathrm{S}}=C_{\mathrm{D}} D_{\mathrm{ST}}$ ), and the final rim diameter is larger than the surface diameter by a factor of $C_{\mathrm{R}}=1.3$ (e.g., $D_{\mathrm{R}}=$ $\left.C_{\mathrm{R}} D_{\mathrm{S}}\right)($ Melosh 1989, 1998). Then,

$$
\begin{gathered}
D_{\mathrm{R}, \text { Strength }}=C_{\mathrm{D}} C_{\mathrm{R}} D_{\mathrm{ST}}=1.56 D_{\mathrm{ST}} \text { and } \\
D_{\mathrm{R}, \text { Gravity }}=\left(D_{\mathrm{R}, \text { Strength }}\right)^{1.18} /\left(D^{*}\right)^{0.18}
\end{gathered}
$$

where the scaling for the final rim diameter in the gravity regime is derived from the lunar crater population (Melosh 1998). The $\pi_{2}$ scaling results for the transient and final crater diameters for a fixed impact velocity and variable projectile size are shown as the solid lines in Fig. 18.

Alternatively, in the strength regime, the transient crater may be scaled by $\pi_{3}$, where: 


$$
\begin{gathered}
\pi_{\mathrm{D}}=C_{3} \pi_{3}^{-\sigma} \\
D_{\mathrm{ST}}=C_{3}\left(\frac{Y}{\rho v_{\mathrm{i}}^{2}}\right)^{-\sigma}\left(\frac{\rho}{m}\right)^{-1 / 3}(\sin \phi)^{1 / 3}
\end{gathered}
$$

The scaling exponents are related to the coupling exponent, $\mu$, of Holsapple and Schmidt (1987) by $\beta=\mu /(2+\mu)$ and $\sigma=\mu /$ 2. The exponent $\sigma$ is related to $\beta$ by $\sigma=\beta /(1-\beta)$, so for competent rock $\sigma=0.28$ for $\beta=0.22$. The effective yield strength of the surface may be estimated using the transition crater rim diameter derived from cratering simulations by O'Keefe and Ahrens (1993),

$$
Y=0.11 D^{*} \rho g \text {. }
$$

For $D^{*}=8.1 \mathrm{~km}, Y=9 \mathrm{MPa}$. The strength scaling curve intersects the gravity scaling curve at $D^{*}$ using a coefficient $C_{3}=0.88$ for competent rock, which is shown as the dashed lines in Fig. 18. Note that, as expected, the diameters of strength-dominated craters are slightly smaller than those predicted from gravity scaling (solid lines).

Because the projectile size is not an observable parameter, we present equations for the transient crater depth and volume and discuss collapse to the observed final crater shape in the next section. In the strength regime, the depth and volume of the transient crater cavity depend on the effective strength of the surface. The maximum depth from the preimpact surface of the transient cavity is related to the yield strength by (O'Keefe and Ahrens 1993):

$$
d_{\mathrm{ST}}=K D_{\mathrm{P}}\left(\frac{Y}{\rho v_{\mathrm{i}}^{2}}\right)^{-\mu / 2}(\sin \phi)^{1 / 3} .
$$

Here the dependence on impact angle is stated explicitly. $K=$ 0.42 is derived from cratering simulations, and the fitted exponent $\mu / 2=0.26$ is reduced slightly from O'Keefe and Ahrens' value of 0.28 to intersect more recently calculated transient cavity depths of $6 D_{\mathrm{P}}$ at $Y /\left(\rho v_{\mathrm{i}}^{2}\right) \sim 3 \times 10^{-5}$, which is typical of Martian impacts (Stewart et al. 2004). Note that the value of $\mu=0.52$ fitted to calculations agrees very well with the range inferred from experiments (Holsapple and Schmidt 1987; Schmidt and Housen 1987).

Using the volume of a paraboloid, $\mathrm{V}=\pi d D^{2} / 8$, the scaling for the transient cavity volume is derived from Equation 4:

$$
\begin{gathered}
\left(\frac{\pi}{8} d_{\mathrm{ST}}\right)^{-1 / 2} V_{T}^{1 / 2}=C_{3}\left(\frac{Y}{\rho v_{i}^{2}}\right)^{-\sigma}\left(\frac{\rho}{m}\right)^{-1 / 3}(\sin \phi)^{-1 / 3} \\
V_{\mathrm{T}}=C_{3}^{2}\left(\frac{\rho}{m}\right)^{-2 / 3}\left(\frac{\pi}{8} d_{\mathrm{ST}}\right)\left(\frac{Y}{\rho v_{\mathrm{i}}^{2}}\right)^{-2 \sigma}(\sin \phi)^{2 / 3}
\end{gathered}
$$

$$
V_{\mathrm{T}}=C_{3}^{2}\left(\frac{\pi}{6}\right)^{2 / 3} \frac{\pi}{8} K D_{\mathrm{P}}^{3}\left(\frac{Y}{\rho \nu_{\mathrm{i}}^{2}}\right)^{-2 \sigma-\mu / 2} \sin \phi
$$

In Equation $7, d_{\mathrm{ST}}$ was replaced by Equation 6 . Note that according to coupling theory, $\sigma=\mu / 2$, so the exponent to the inverse Cauchy number is $-3 \sigma$. The fitted values of $\mu / 2$ to simulations and $\sigma$ to experiments are nearly equal.

Here, we assume that the diameter and depth scaling constants $\left(C_{3}, \sigma, K, \mu\right)$ are weakly dependent on the yield strength. The variation in $C_{3}$ and $\sigma$ is small over a wide range of materials (water, sand, and competent rock) (Schmidt and Housen 1987), and $K$ and $\mu$ are constants fit to a 4 order of magnitude range of the inverse Cauchy number (O'Keefe and Ahrens 1993). Then, from Equation 7, $V_{\mathrm{T}} \sim Y^{-3 \sigma}, D_{\mathrm{ST}} \sim Y^{-\sigma}$, and $d_{\mathrm{ST}} \sim Y^{-\sigma}$. As the yield strength increases, the depth and diameter of the transient cavity decrease at a similar rate, and the overall cavity volume decreases by approximately $V \sim 1 / Y$ for $\sigma \sim 1 / 3$. In Fig. 18, the dotted line illustrates a 33\% increase in the effective yield strength of the surface $(Y=12$ $\mathrm{MPa})$. The stronger surface results in smaller craters compared to the $9 \mathrm{MPa}$ surface (dashed line) for the same impact parameters. Note that the final crater diameter curve is offset from the gravity regime curve although the transient crater diameter intersects the gravity regime curve. An effective yield strength of $12 \mathrm{MPa}$ leads to a strength to gravity regime transition rim diameter of $10.5 \mathrm{~km}$, which is around the upper end of the observed range of transition diameters on Mars.

\section{Regional Differences in Simple Crater Collapse}

To compare the scaling laws to the crater geometry measurements in the strength regime, the volume and depth of the final simple crater must be related to the transient crater cavity. We assume that the collapse process is similar for all simple craters in the size range considered here (about 4$10 \mathrm{~km}$ surface diameter). Crater collapse decreases the cavity volume and increases the cavity diameter, such that

$$
\begin{gathered}
D_{S}=C_{D} D_{\mathrm{ST}} \\
V_{\text {Cavity }}=C_{\mathrm{V}} V_{\mathrm{T}}
\end{gathered}
$$

Here $V_{\mathrm{T}}$ is defined by Equation 7 and $D_{\mathrm{ST}}$ is defined by Equation 4. Since both the transient and final crater cavities are approximately paraboloid, $C_{\mathrm{D}}$ and $C_{\mathrm{V}}$ are related by:

$$
\begin{gathered}
\frac{\pi}{8} d_{\mathrm{S}} D_{\mathrm{S}}^{2}=C_{\mathrm{V}} \frac{\pi}{8} d_{\mathrm{ST}} D_{\mathrm{ST}}^{2} \\
\frac{d_{\mathrm{S}}}{D_{\mathrm{S}}} D_{\mathrm{S}}^{3}=C_{\mathrm{V}}\left[\frac{K}{C_{3}}\left(\frac{\pi}{6}\right)^{-1 / 3} D_{\mathrm{ST}}\right] D_{\mathrm{ST}}^{2}
\end{gathered}
$$




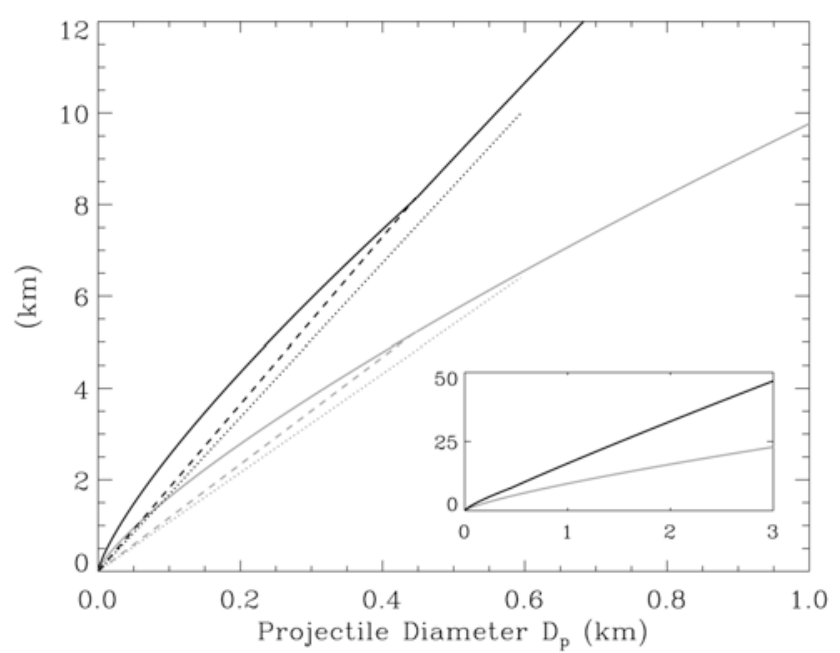

Fig. 18. $\pi$-scaled transient surface diameter (gray lines) and final rim diameter (black lines) in the gravity regime (solid lines and inset) and strength regime (effective strength: $Y=9 \mathrm{MPa}$ is dashed; $Y=12 \mathrm{MPa}$ is dotted) as a function of projectile diameter, $D_{\mathrm{P}}$, for $10 \mathrm{~km} \mathrm{~s}^{-1}$ impacts at 45 degrees.

$$
\begin{gathered}
\frac{d_{\mathrm{S}}}{D_{\mathrm{S}}} D_{\mathrm{S}}^{3}=C_{\mathrm{V}}\left(0.59 D_{\mathrm{ST}}\right) D_{\mathrm{ST}}^{2} \\
\frac{d_{\mathrm{S}}}{D_{\mathrm{S}}} C_{\mathrm{D}}^{3} D_{\mathrm{ST}}^{3}=0.59 C_{\mathrm{V}} D_{\mathrm{ST}}^{3} \\
C_{\mathrm{D}}=\left[\frac{0.59 C_{\mathrm{V}}}{\left(\frac{d_{\mathrm{S}}}{D_{\mathrm{S}}}\right)}\right]^{\frac{1}{3}}
\end{gathered}
$$

The derivation includes the substitution from Equations 6 and 7 of $d_{\mathrm{ST}}=0.59 D_{\mathrm{ST}}$ for $K=0.42, C_{3}=0.88$, and $\sigma=\mu / 2$. Note that the coefficient relating $d_{\mathrm{ST}}$ and $D_{\mathrm{ST}}$ is weakly dependent on the effective yield strength.

Scaling the final crater volume by $0<C_{\mathrm{V}}<1$ includes collapse of the transient crater to the final crater shape and bulking of the slumped material. Reasonable values of $C_{\mathrm{V}}$ will not be near 0 or $1 . C_{\mathrm{D}}$ is constrained to be a modest increase of the transient surface diameter to the final surface diameter for simple craters based on experiments and simulations (e.g., $1.1<C_{\mathrm{D}}<1.3$ ). Fits to the observed values of $d_{\mathrm{S}} / D_{\mathrm{S}}$ are shown in Fig. 10 . Because $d_{\mathrm{S}} / D_{\mathrm{S}}$ is not constant, $C_{\mathrm{D}}$ and $C_{\mathrm{V}}$ cannot both be constant. Alternatively, the final diameter and cavity volume may have a weak power law dependence on the transient cavity diameter and volume in Equation 8.

Using the $d_{\mathrm{S}} / D_{\mathrm{S}}$ fit to Solis Planum (Table 2) in Equation 9, we fit $C_{\mathrm{D}}$ and $C_{\mathrm{V}}$ in Equation 8 to match the crater geometry measurements, shown in Fig. 19. The crater size scaling parameters are the same as used in the $Y=9 \mathrm{MPa}$ case

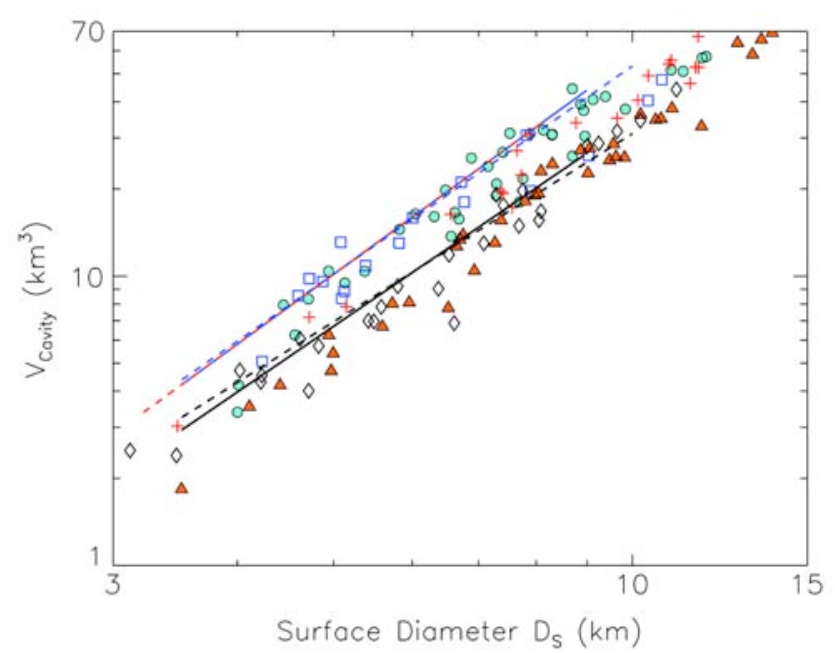

Fig. 19. Crater diameter and volume fits (Equations 8 and 9) for simple highland craters (black lines) and simple lowland craters (blue lines). The offset between the highland and lowland craters is a result of differences in both the crater cavity shape and crater collapse processes. The dashed red line indicates the shift to smaller volumes in the lowland fit (the solid blue line) for a change in effective yield strength from 9 to $12 \mathrm{MPa}$.

presented in the previous section (dashed line in Fig. 18). The highland data are fit with $C_{\mathrm{V}}=0.35$ and $1.1<C_{\mathrm{D}}<1.3$ for increasing $D_{\mathrm{S}}$ (solid black line), $C_{\mathrm{D}}=1.2$ and $0.5>C_{\mathrm{V}}>0.25$ (dashed black line), or a continuous function of $C_{\mathrm{D}}$ and $C_{\mathrm{V}}$ over a similar range of values.

Using the $d_{\mathrm{S}} / D_{\mathrm{S}}$ fit to Utopia (Table 2), the lowland craters cannot be fit with the same $C_{\mathrm{V}}=0.35$ derived for the highlands because the value of $C_{\mathrm{D}}$ becomes nonphysical $\left(0.95<C_{\mathrm{D}}<1.3\right)$ by Equation $9 . C_{\mathrm{D}}$ cannot be less than 1 by definition. Hence, $C_{\mathrm{V}}$ must be larger for lowland craters than highland craters. The lowland data are fit with $C_{\mathrm{V}}=0.6$ and $1.1<C_{\mathrm{D}}<1.3$ (solid blue line in Fig. 19) or $C_{\mathrm{D}}=1.2$ and $0.7>$ $C_{\mathrm{V}}>0.45$ (dashed blue line) for increasing $D_{\mathrm{S}}$.

Note that when the shape of the crater is constant $\left(d_{\mathrm{S}} / D_{\mathrm{S}}\right.$ $=$ constant), changing the effective yield strength of the surface maintains the slope of $V_{\text {Cavity }}$ versus $D_{\mathrm{S}}$ in Fig. 19 . For the same impactor population, decreasing the yield strength shifts the population of craters to larger volumes (up and to the right along the same line), while increasing the yield strength shifts the population to smaller volumes along the same line (Equation 7). Therefore, the offset between the highland and lowland craters in Fig. 19 must reflect the different $d_{\mathrm{S}} / D_{\mathrm{S}}$ ratios for the highland and lowland populations. In Fig. 19, the dashed red line illustrates a 33\% increase in the effective yield strength compared to the solid blue line.

The increase in $C_{\mathrm{V}}$ required to fit lowland data demonstrates that the freshest craters in the lowlands have experienced less transient cavity collapse compared to the freshest highland craters. Craters formed in stronger materials collapse less, suggesting that the lowland surfaces are 
stronger than the highland surfaces in this study. Craters in the lowlands preserve $45-70 \%$ of the transient crater volume compared to $25-50 \%$ in the highlands. The larger depth-todiameter $\left(d_{\mathrm{S}} / D_{\mathrm{S}}\right)$ and rim height-to-diameter $\left(H_{\mathrm{R}} / D_{\mathrm{R}}\right)$ ratios in the lowlands reflect stronger surface materials and less crater collapse compared to the highlands. Concurrently with our own work, Boyce et al. (2006) also inferred the presence of high target strength materials in Isidis and southwestern Utopia from crater depth-to-diameter relationships.

\section{Comparison to Simple Terrestrial and Lunar Craters}

The rim depth-to-rim diameter ratio $\left(d_{\mathrm{R}} / D_{\mathrm{R}}\right)$, rim heightto-rim diameter ratio $\left(H_{\mathrm{R}} / D_{\mathrm{R}}\right)$, and crater volume collapse coefficient $\left(C_{\mathrm{V}}\right)$ for the freshest simple Martian lowland craters are similar to those for fresh simple craters on Earth. Estimates of the breccia lens and transient crater volumes at Meteor Crater (Arizona, USA) and Brent Crater (Ontario, Canada) indicate that $C_{\mathrm{V}} \sim 0.5$ (Grieve and Garvin 1984), in excellent agreement with the $C_{\mathrm{V}}$ values for the Martian lowlands and at the upper limit for the range of $C_{\mathrm{V}}$ values for the highland craters.

The average value of $d_{\mathrm{R}} / D_{\mathrm{R}}$ for Martian lowland craters with $D_{\mathrm{R}}<8 \mathrm{~km}$ is $0.20 \pm 0.02(1 \sigma)$ (Fig. 9b), which is similar to the average $\left(d_{\mathrm{R}} / D_{\mathrm{R}}\right)=0.15 \pm 0.02$ of six relatively uneroded terrestrial craters in the size range $0.39 \leq D_{\mathrm{R}} \leq 2.44 \mathrm{~km}$ (Fudali et al. 1980). Fresh simple lunar craters have $d_{\mathrm{R}} / D_{\mathrm{R}} \sim$ 0.196 , and the $d_{\mathrm{R}} / D_{\mathrm{R}}$ value is independent of crater size in the strength regime (Pike 1977). The rim height ratio $H_{\mathrm{R}} / D_{\mathrm{R}}$ for Martian lowland craters with $D_{\mathrm{R}}<8 \mathrm{~km}$ is $0.041 \pm 0.005$ (Fig. 12b). The six fresh terrestrial craters studied by Fudali et al. (1980) have very similar values, $H_{\mathrm{R}} / D_{\mathrm{R}}=0.046 \pm 0.011$. Measurements of fresh simple lunar craters yield $H_{\mathrm{R}} / D_{\mathrm{R}}$ 0.036, nearly independent of crater size (Fig. 12b) (Pike 1977). The nearly constant $d_{\mathrm{R}} / D_{\mathrm{R}}$ and $H_{\mathrm{R}} / D_{\mathrm{R}}$ ratios for simple craters is indicative of strength-dominated crater shape, where the gravity on the three different planetary bodies had a minor role during crater collapse. However, the fresh simple craters in the Martian highland plains do not have a constant $d_{\mathrm{R}} / D_{\mathrm{R}}$ ratio. Instead, the $d_{\mathrm{R}} / D_{\mathrm{R}}$ trend is similar to an extrapolation from the fits in the gravity regime.

Three lines of evidence indicate that the surface materials are substantially stronger in the Martian lowlands compared to the highlands: 1) The observed fresh simple crater shapes indicate that craters in the Martian lowlands experienced less crater collapse compared to highland craters, and the lowland values of $0.45<C_{\mathrm{V}}<0.7$ are similar to those of one of the best-preserved craters on Earth, Meteor Crater; 2) The $H_{\mathrm{R}} / D_{\mathrm{R}}$ ratio for Martian simple craters is weakly independent of crater size. The ratio is similar to fresh lunar and terrestrial craters, and craters in Utopia and Isidis have higher crater rims in the $7<D_{\mathrm{R}}<11 \mathrm{~km}$ range compared to the other study regions; and 3) The $d_{\mathrm{R}} / D_{\mathrm{R}}$ ratio is substantially larger for simple craters in the lowlands (by a factor of 1.5 to 2.0), nearly independent of crater size, and similar to fresh craters on Earth and the Moon. By contrast, the inconstant $d_{\mathrm{R}} / D_{\mathrm{R}}$ ratios in the highlands follow extrapolation from the gravity regime.

\section{Regional Differences in Effective Surface Strength}

Quantifying the difference in the effective strength between the highland and lowland surfaces is difficult. One approach that provides a broad estimate for the strength of a planetary surface is to examine the simple-to-complex crater transition size. Using $1 / g$ scaling from the Moon, the simple to complex transition is expected to be around $8 \mathrm{~km}$ rim diameter. However, Viking-based studies of 11 interior characteristics of 230 craters indicate that the global average is significantly smaller: $5.1_{-1.9}^{+3.1} \mathrm{~km}$ (Pike 1988). More recent measurements of $\sim 6000$ craters using the MOLA data suggest (primarily on the basis of accurate $d_{\mathrm{R}} / D_{\mathrm{R}}$ measurements) that the global mean is centered at about $7 \mathrm{~km}$ with significant regional differences (Garvin et al. 2003; Garvin et al. 2002). Note that the simple and complex fits to $d_{\mathrm{R}} / D_{\mathrm{R}}$ by Garvin et al. (2003) (Fig. 9) intersect at $5.4 \mathrm{~km}$, closer to the $3.1_{-0.5}^{+0.7} \mathrm{~km}$ intersection between small and large crater depth to diameter fits derived by Pike (1988). The primary difficulties in determining the true depth around small craters using the MOLA data are the rare alignment of an altimetry profile through the centers of small craters and the $\sim 300 \mathrm{~m}$ along track spacing of the altimetry points. Therefore, it is difficult to use the MOLA data alone to identify depth-todiameter transitions around small craters. Several research groups have noted that there are lowland regions with large simple craters up to $D_{\mathrm{R}} \sim 10.2 \mathrm{~km}$ (Boyce et al. 2005a; Boyce et al. 2006; Garvin et al. 2000; Pike 1980), significantly beyond the average transition diameter. In this study, measurements of $d_{\mathrm{R}}, H_{\mathrm{R}}$, and $V_{\text {Cavity }}$ indicate that the freshest lowland craters have a transition diameter as large as $10 \mathrm{~km}$, with a transition range of $8-10 \mathrm{~km}$.

In the highland regions of this study, there is no break in crater parameters similar to the obvious transition in the lowland craters using the MOLA data. For these regions, we rely on previous work by Pike (1980) to estimate the transition diameter. First, note that the depth-to-diameter ratio for our highland regions follow the global trends established using the Viking imagery data (Fig. 9). Thus, the deep, simple craters identified in Isidis and Utopia are anomalous compared to the global crater population. Our measured highland crater data sets show no transition in the wellresolved size range $\geq 6$ rim diameter and indicate that the transition size is less than $6 \mathrm{~km}$. Pike's global estimate of a $5.1 \mathrm{~km}$ strength to gravity transition rim diameter and $3.1 \mathrm{~km}$ intersection between power law fits in each region are presently the best estimate for the transition diameter of the highland regions in this study.

Pike (1988) suggested that the global simple-to-complex 
transition diameter on Mars falls short of the $1 / g$ trend formed by Earth, Mercury, and the Moon because of the presence of weak, layered, and volatile-rich materials on the surface. Using Equation 5, the range of effective yield strengths on the surface of Mars is $\sim 3-11 \mathrm{MPa}$ for transition rim diameters between 3 and $10 \mathrm{~km}$, the range observed from Viking and MOLA-based studies. The lowest strength estimate is significantly weaker than the range of effective strengths for "soft" (e.g., sedimentary) to "hard" (e.g., crystalline) rocks, 7.6-18 MPa, and stronger than "wet soil" at $1.14 \mathrm{MPa}$ (Holsapple 1993). Therefore, portions of the Martian surface have effective strengths that lie between soils and weak rocks, lending support to the interpretation of weak, layered, and/or volatile-rich materials.

The presence of $10 \mathrm{~km}$ rim diameter simple craters in the lowlands indicates that these regions have a surface layer with an effective strength within the soft-to-hard rock range. There is a striking concentration of large simple craters in Utopia basin. For a given population of impactors, the final crater volumes are inversely proportional to the yield strength (Equation 7). The effect of increasing the yield strength from 9 to $12 \mathrm{MPa}$ on the cavity volume to diameter relationship is shown as the dashed red line in Fig. 19, which shifts the solid blue line down and left along the same slope. Hence, the increase in strength does not change the result of the crater collapse analysis and supports the inference of less crater collapse in the lowlands compared to the highland regions.

The nearly constant $d_{\mathrm{R}} / D_{\mathrm{R}}$ of simple craters throughout southern Utopia basin indicates that this population of craters formed within a layer of consistent strength. The thickness of this layer must be $>6.5 \mathrm{~km}$, based on the depth of the transient cavity for final $10 \mathrm{~km}$ rim diameter craters at a mean impact velocity for Mars (Fig. 18). Boyce et al. (2006) suggest that an extensive, $\sim 1-2 \mathrm{~km}$ thick, olivine-rich mafic-to-ultramafic rock unit identified by thermal emission spectroscopy in the Nili Fossae region (Hamilton and Christensen 2005; Hamilton et al. 2003; Hoefen et al. 2003) may be responsible for the relatively strong subsurface implied by the crater geometries in Isidis and Utopia. However, unless the olivine-rich unit is much thicker than currently observed, it alone cannot account for the crater observations. In addition, Hesperian volcanic flooding and sedimentary (Vastitas Borealis Formation) deposits and Amazonian volcanic deposits from Elysium form shallow layers within the upper $1 \mathrm{~km}$ of the Utopia basin (Thomson and Head 2001). The size range of observed fresh crater forms cannot be controlled by these young surface deposits. Instead, the stronger layer controlling the shape of 4 to $10 \mathrm{~km}$ surface diameter Utopian craters must be the primary sedimentary or volcanic fill that was deposited in Utopia near the end of the Noachian period. The Utopia basin has a positive free-air gravity anomaly similar to lunar mascons (Smith et al. 1999), and geophysical models of the primary infill in the basin are best fit with a layer of material about $20 \mathrm{~km}$ thick (Searls and Phillips 2004). Unless the basement of Utopia basin has very similar properties to the Noachian infill, the cratering record supports a thick layer of infill rather than a thin $(<$ several $\mathrm{km})$ layer. Note that if the observed quasi-circular depressions (buried impact craters) all formed on the original floor of the Utopia basin, the Noachian infill must be less than a few kilometers thick (Buczkowski et al. 2005). The effect of Hesperian and Amazonian volcanic and sedimentary deposits on Utopia crater forms is discussed in Black and Stewart (Forthcoming).

Because the $d_{\mathrm{R}} / D_{\mathrm{R}}$ ratio and $V_{\text {Cavity }}$ values of simple craters in Isidis basin and Acidalia Planitia are similar to Utopian craters of the same diameter, we infer that the effective strengths of the surfaces are similar. The proximity of Isidis basin to Utopia suggests that widespread Noachian volcanic or sedimentary process acted on both basins. Isidis does not contain deep simple craters are large as found in Utopia, perhaps indicating that the infill materials are thinner. The cavity volumes of simple craters in Acidalia fall between the trends for Isidis/Utopia and Lunae Planum/Solis Planum (Fig. 19). Acidalian simple craters apparently underwent slightly more collapse than craters in Isidis and Utopia, but less collapse than craters on the highland plateaus. Therefore, the material below the Vastitas Borealis Formation in Acidalia has an intermediate strength compared to the other terrains.

Lunae Planum and Solis Planum are part of the Noachian plateau sequence in the western highlands and covered by Hesperian ridged plains materials (Scott and Tanaka 1986). The highland plateau is composed of at least seven units identified as fractured, heavily cratered, dissected, ridged, and rough terrains deposited by volcanic and eolian processes. Recent images of the highlands indicate that areas of the highland plateaus contain up to 4 kilometers of Noachian sedimentary deposits (Malin and Edgett 2000). The heavily fractured, layered materials may have hosted a complex subsurface hydrological system driven by Tharsis magmatism (Rodriguez et al. 2005). The Noachian stratigraphy is consistent with the interpretation by Pike (1988) that the simple-to-complex crater transition diameter on Mars, which lies below $1 / \mathrm{g}$ scaling from Earth, Mercury, and the Moon, is due to weak, layered, and possibly volatile-rich materials.

The thickness of the ridged plains materials $(\mathrm{Hr})$ in Lunae Planum is estimated to be between 300 and $600 \mathrm{~m}$ thick (Frey et al. 1991). More recent work using buried impact craters indicates that western Solis Planum may have a thicker deposit, possibly several kilometers thick (Frey et al. 2002a). The difference in the thickness of the youngest layer may be reflected in slightly deeper cavities for the smallest simple craters in Solis Planum (Fig. 9). For a relatively thin or weakened $\mathrm{Hr}$ deposit, the depth-to-diameter and volume measurements follow smooth trends from the gravity regime down to craters a few kilometers in diameter. The inference of effective strength between soils and competent rock applies to the heavily fragmented layers in the plateau. Note that the freshest highland craters in this 
study are not shallower than the lowland craters because of the presence of a buried stronger layer, an effect that has been seen on the Moon (Quaide and Oberbeck 1968) and in laboratory experiments (Piekutowski 1977). Because the depth-to-diameter ratios for highland craters follow a similar power law over the size range 3 to $50 \mathrm{~km}$ rim diameter, there is no observational evidence for a strong buried layer effecting the measurements of the freshest craters in this study.

Although the estimates of surface strength provided here are coarse, analyses of crater geometries can contribute quantitative information about the regional geology on Mars. Using crater geometries to interpret surface strength relies upon the preservation of some fresh craters on Mars and the assumption of similar impactor populations for all fresh craters. Partial or differential degradation of the freshest craters at different locations on Mars would contribute to the error in determining the transition diameter between strengthand gravity-dominated craters and estimates of the magnitude of crater collapse. The inferred values for the collapse coefficient, $c_{\mathrm{D}}$, could be interpreted as lower limits, as gradational effects reduce the volume of the crater cavity. However, because the inferred collapse coefficient agrees well with fresh terrestrial craters, no systematic degradation effects are resolved by our analyses, and we infer that the preservation level of the freshest population of craters on Mars is suitable for geometrical analyses. Because the differences in geometries between craters in the highland and lowland regions are much larger than the observed natural variability in the measured crater parameters (which includes partial and heterogeneous degradation), we conclude that the inferred differences in crater collapse and target strength are resolved. As our understanding of crater collapse improves, the crater collapse volume may be a more useful parameter for inferring the surface strength in future studies.

As an aside, we note that the inference of strong and weak surfaces from the distribution of Martian meteorites (Head et al. 2002) applies to surface layers and not subsurface layers as discussed above. Also, the shape of fresh crater cavities is not necessarily correlated with the youngest surface deposits, and care must be taken when associating crater geometric properties with the geologic terrain.

\section{EJECTA VOLUMES AND THE Z-EDOZ MODEL}

Almost all fresh craters in this study exhibit fresh rampart-type ejecta blankets. Ejecta volume measurements can be used to constrain theories for the formation of fluidized ejecta. The dynamics of Martian ejecta blankets have been compared to terrestrial debris flows and landslides (BarnouinJha et al. 2005; Ivanov 1996) and also to gas-supported flows similar to volcanic base surges (Mouginis-Mark 1981; Schultz 1992; Schultz and Gault 1979). In this section, we address the appropriate scaling for the amount of ballistic ejecta required to form the observed ejecta blankets around fresh Martian craters. We also assess the effects of incorporating surface materials into the ejecta flow and concentration of material in the continuous ejecta blanket by nonballistic processes.

\section{The Z-EDOZ Model}

Maxwell's Z model is an empirical, analytical model used to describe the excavation flow field of the transient cavity (Maxwell 1973, 1977). This simple, predictive model has been used to describe the starting conditions for calculations of the ejecta blanket flow, assuming ballistic ejection (e.g., Ivanov 1996), and the collapse of the transient cavity to the final crater shape (Melosh and Ivanov 1999). Here we compare the observed ejecta and uplifted surface volumes to the predictions of the $\mathrm{Z}$ model.

In the original $\mathrm{Z}$ model, target material emerging at a radius, $r_{\mathrm{S}}$, follow spiral trajectories from the impact point according to:

$$
r=r_{\mathrm{S}}(1-\cos \theta)^{1 /(\mathrm{Z}-2)}
$$

where $r$ and $\theta$ are polar coordinates with the $\theta=0$ axis pointing vertically down. $r_{\mathrm{S}}$ is the radial distance from the impact point along the preimpact surface and the point where the trajectory cuts the surface. The excavation flow is described by a collection of trajectories or stream tubes where $r_{\mathrm{S}}$ varies from 0 to the radius of the transient cavity, $R_{\mathrm{ST}}$. The value of $Z$ defines the curvature in the flow field. Realistic limits on crater-scaling laws limit the range of $Z$ to greater than 1.5 and less than 3.0 (Holsapple and Schmidt 1982). Comparisons to experiments and calculations show that $2.5<$ $Z<3$.0. For a constant value of $Z$, the ejection angle at the preimpact surface is the same throughout the transient cavity with a value of $\varphi=\arctan (Z-2)$.

Major refinements to the original $\mathrm{Z}$ model include centering the flow below the impact surface and varying the value of $Z$ with time during the excavation of the transient cavity (Croft 1980; Thomsen et al. 1979; Thomsen et al. 1980). The depth of the effective center of $Z$ model flow (EDOZ) is about one projectile diameter. Due to the momentum of the projectile, impact craters are similar to explosion craters with the charge buried at shallow depths (Melosh 1989). The depth of burial corresponds physically to the isobaric core in the pressure field generated by the shock wave from the impact (Ahrens and O'Keefe 1987; Pierazzo and Melosh 2000; Pierazzo et al. 1997). Moving the center of flow beneath the surface results in an increase in the total excavated volume and higher ejection angles. A schematic of the Z-EDOZ flow field is shown in Fig. 20a. Recent comparisons between the Z-EDOZ model and ejection angles from oblique impact experiment show that the early time flow field for $45^{\circ}$ impacts deviates slightly from the axisymmetric 

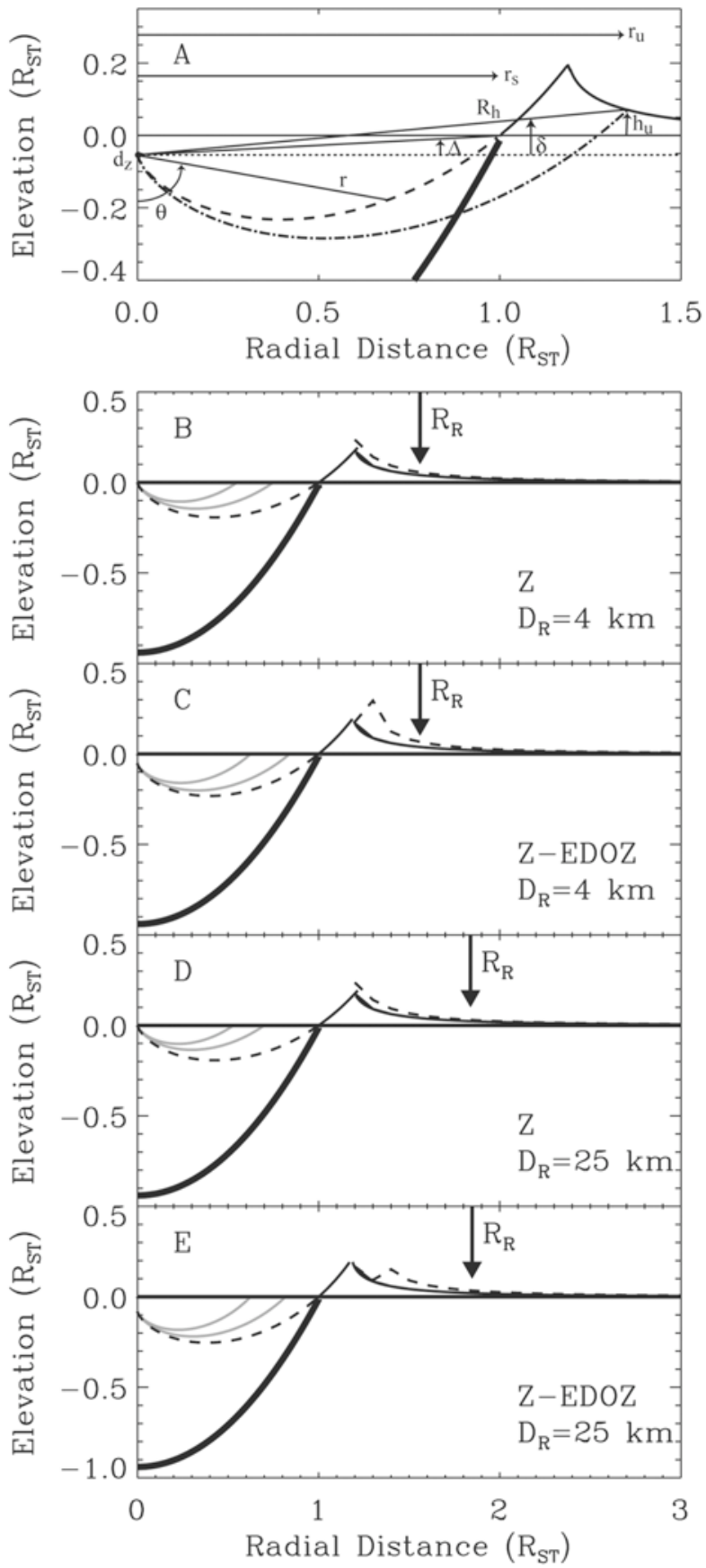

Fig. 20. a) A schematic of the Z-EDOZ model variables: $d_{\mathrm{Z}}=$ depth to center of flow; $\theta, r=$ polar coordinates along flow trajectories; $r_{\mathrm{S}}$ $=$ horizontal distance where single trajectory meets surface; $\Delta=$ angle from center of flow to surface at distance $r_{\mathrm{S}} ; R_{\mathrm{h}}=$ distance from flow center to uplifted surface point $\left(r_{\mathrm{u}}, h_{\mathrm{h}}\right) ; \delta=$ angle from flow center to uplift point; $R_{\mathrm{ST}}=$ surface radius of transient crater. b-e) $\mathrm{Z}$ and Z-EDOZ model excavation zones (dashed lines), uplift profiles (solid line above surface) and ejecta thickness (dashed lines above uplift profiles) for final crater radii of $2 \mathrm{~km}$ and $12.5 \mathrm{~km}$, normalized to $R_{\mathrm{ST}}$. The thick line outlines the transient crater cavity, and the vertical arrow locates the final crater radii, $R_{\mathrm{R}}$ (Equation 3$)$. The inner and outer grey trajectories identify the source of ejecta reaching $3 R_{\mathrm{R}}$ and $1 R_{\mathrm{R}}$, respectively. model (Anderson et al. 2004). At late times during crater excavation, the component of momentum-driven flow from the projectile trajectory is negligible and the assumption of axisymmetry provides a good comparison to azimuthally integrated crater measurements.

In the constant Z-EDOZ model, the flow field originates from a constant depth, $d_{Z}$, throughout the excavation process. Croft (1980) found that $Z$ decreases with time and reaches a constant value between 2.5 and 3.0 at about half the transient cavity radius. Properties of the constant Z-EDOZ flow field are derived by Croft (1980; Appendix A.). The Z-EDOZ flow field intersects the preimpact surface with ejection angles that decrease with increasing radius:

$$
\varphi=\arctan \left[\frac{\frac{\tan \Delta}{\cos \Delta}-\tan ^{2} \Delta+(Z+2)}{\frac{1}{\cos \Delta}-\tan \Delta(Z-1)}\right]
$$

where $\Delta$ is the angle between the horizontal plane at depth $d_{\mathrm{Z}}$ and the point where the stream tube intersects the preimpact surface (Fig. 20a). When $d_{Z}=0, \Delta=0$ and the ejection angle is reduced to a constant $\varphi=\arctan (Z-2)$ as in the original $Z$-model. The angle $\Delta$ needs to be solved numerically for the Z-EDOZ trajectory emerging at each $r_{\mathrm{S}}$, and the value of $\Delta$ decreases with increasing $r_{\mathrm{S}}$. The excavated volume outlined by an Z-EDOZ trajectory emerging at $r_{\mathrm{S}}$ is given by:

$$
V_{\mathrm{Z}, \mathrm{r}_{\mathrm{S}}}=\left[\frac{\pi}{3} \frac{d_{\mathrm{Z}}}{r_{\mathrm{S}}}+\frac{2 \pi(Z-2)}{3(Z+1)} \frac{1+\sin \Delta}{\cos ^{3} \Delta}\right] r_{\mathrm{S}}^{3} .
$$

Example Z-EDOZ trajectories are shown in Figs. 20c and $20 \mathrm{e}$. Note that the Z-EDOZ stream tubes reach greater depths compared to the original $\mathrm{Z}$ model (Figs. 20b and 20d).

The ejection velocity, $v_{\mathrm{e}}$, for each stream tube is usually described by the power law:

$$
v_{\mathrm{e}}=v_{\mathrm{ST}}\left(\frac{R_{\mathrm{ST}}}{r_{\mathrm{S}}}\right)^{\mathrm{m}}
$$

where $2.5<m<3.0$ (Ivanov 1996), and $v_{\mathrm{ST}}$ is the velocity at the radius of the transient cavity, $R_{\mathrm{ST}}$. By equating the kinetic energy in a stream tube with the potential energy, Ivanov derives $v_{\mathrm{ST}}=\sqrt{k g R_{\mathrm{ST}}}$, where $g$ is the gravitational acceleration and $k=[(Z-2)(Z+1)] /[Z(Z+2)]$. For the size range of craters considered here, $v_{\mathrm{ST}}$ is typically several $10 \mathrm{~s} \mathrm{~m} \mathrm{~s}^{-1}$.

The $\mathrm{Z}$ and Z-EDOZ model ejecta thickness around the transient crater is calculated assuming ballistic trajectories and shown as the dashed lines above the uplifted surface in Figs. $20 \mathrm{~b}-\mathrm{e}$. The final crater rim radius, $R_{\mathrm{R}}$, is calculated from Equation 3 and shown as the vertical arrows in Figs. 20b-e for final crater radii of 2 and $12.5 \mathrm{~km}$. Uplifted and ejected 
materials within $R_{\mathrm{R}}$ collapse back into the final crater cavity. In Fig. 20, dimensions are scaled to the transient crater surface radii, $R_{\mathrm{ST}}$. The thick solid line outlines the paraboloid transient crater cavity, and the dashed trajectory outlines the excavated region, where $r_{\mathrm{S}}=R_{\mathrm{ST}}$.

\section{Comparison to Observations and Improving the Scaling Relationships}

The median radius of the distal edge of the continuous ejecta blankets measured around the freshest craters is about $3 R_{\mathrm{R}}$ (mean $3.5 R_{\mathrm{R}}$ with a $1 \sigma$ scatter of $0.9 R_{\mathrm{R}}$ ). Here, we define the volume of ballistic ejecta in the continuous ejecta blanket, $V_{\mathrm{BE}}$, as the volume of ejecta that lands between $1 R_{\mathrm{R}}$ and $3 R_{\mathrm{R}}$. In Fig. 20, the inner grey stream tube locates the source of ejecta reaching a distance of $3 R_{\mathrm{R}}$, and the outer grey stream tube reaches a distance of $1 R_{\mathrm{R}}$. The continuous ejecta volumes measured for the freshest craters in this study are presented in Fig. 21 with the ballistic ejecta volumes for $Z=$ 2.7 for both the Z (black line) and Z-EDOZ (green lines) models. The volume of ejecta predicted by each model is significantly less than that inferred from the data. The original $\mathrm{Z}$ model is a very poor fit to the data. The Z-EDOZ model, with $d_{\mathrm{z}} \sim 0.9 D_{\mathrm{P}}$ using $\pi_{2}$ scaling, is a better fit (solid green line). However, only with a very generous bulking factor of 2 (dashed green line) does the Z-EDOZ model approach the lowest ejecta volume measurements.

The ballistic ejecta with a range between $1 R_{\mathrm{R}}$ and $3 R_{\mathrm{R}}$ is only a fraction of the total excavated volume, $V_{\mathrm{EXC}}$. Using the Z-EDOZ model with $Z=2.7$ and $d_{\mathrm{z}} \sim 0.9 D_{\mathrm{P}}$ for final craters with diameters between 3 and $50 \mathrm{~km}$, the fraction of ejecta emplaced ballistically near the transient crater rim at radii within the collapsed final crater $\left(<R_{\mathrm{R}}\right)$ is about $33 \%$ of the total excavated volume. The remaining volume of ejecta is distributed equally between $1 R_{\mathrm{R}}$ and $3 R_{\mathrm{R}}$ and distances greater than $3 R_{\mathrm{R}}$, so $V_{\mathrm{BE}} \sim V_{\mathrm{EXC}} / 3$. We note that the larger radii of continuous ejecta blankets on Mars compared to Mercury and the Moon may be the result of significant horizontal flow after ballistic emplacement, and the initial mass of the flow may be less than $V_{\mathrm{BE}}$. Here, we compare the observed continuous ejecta range with the same ballistic range assuming that all materials within $1 R_{\mathrm{R}}$ and $3 R_{\mathrm{R}}$ were incorporated into the continuous ejecta. The approximately equal volume distribution between ballistic ranges within the final crater rim, in the continuous ejecta blanket, and in the distal ejecta can be seen in Figs. 20c-e by comparing the relative volumes between the grey trajectories and dashed trajectory. Even if all of the ejecta with initial ballistic range beyond $3 R_{\mathrm{R}}$ were collected into the continuous ejecta blanket, perhaps through atmospheric interactions (e.g., Schultz 1992), the volume increase is not sufficient to match the observations. Since the atmospheric concentration of ejecta is not expected to be extremely efficient, there is a significant discrepancy between the $\mathrm{Z}$ and Z-EDOZ models and the observations.
Because of the uncertainties in the measurement of the ejecta volume, the sum of ejecta and uplifted volume provides a more robust comparison between the Z-EDOZ model and the data. The uplifted surface is calculated by equating the volume of stream tube in the transient cavity with the volume displaced at the surface for stream tubes emerging at $r_{\mathrm{S}}>R_{\mathrm{ST}}$. The range, $r_{\mathrm{u}}$, the uplift height, $h_{\mathrm{u}}$, are given by:

$$
\begin{gathered}
h_{\mathrm{u}}=R_{\mathrm{h}} \sin \delta-d_{\mathrm{Z}} \\
r_{\mathrm{u}}=R_{\mathrm{h}} \cos \delta
\end{gathered}
$$

$R_{\mathrm{h}}$ is the distance between the center of the flow, $d_{\mathrm{Z}}$, and the uplift location $\left(r_{\mathrm{u}}, h_{\mathrm{u}}\right)$, and $\delta$ is the angle from the horizontal plane at depth $d_{\mathrm{Z}}$ and point $\left(r_{\mathrm{u}}, h_{\mathrm{u}}\right)$ (Fig. 20a). The angle $\delta$ is defined by:

$\sin \delta=\left[\left(1-\cos \theta_{\mathrm{i}}\right)^{\frac{(Z+1)}{(Z-2)}}+(1-\sin \Delta)^{\frac{(Z+1)}{(Z-2)}}\right]^{\frac{(Z-2)}{(Z+1)}}-1$

where $\theta_{i}$ is the polar angle to the point where the stream tube intersects the transient cavity, e.g., at the intersection of the dot-dashed line and thick solid line in Fig. 20. Here, we assume the transient cavity is parabolic with a depth of $0.94 R_{\mathrm{ST}}$ (Equation 6). See Croft (1980) for a detailed derivation of the Z-EDOZ parameters. $V_{\mathrm{Up}}$ is the volume of uplifted material between $1 R_{\mathrm{R}}$ and $3 R_{\mathrm{R}}$. The total volume above the preimpact surface between $1 R_{\mathrm{R}}$ and $3 R_{\mathrm{R}}$ predicted by the Z-EDOZ model, $V_{\mathrm{Z} \text {-Above, is the sum of }}$ $V_{\mathrm{Up}}$ and $V_{\mathrm{BE}}$.

The measured $V_{\text {Above }}$ for the freshest Martian craters is compared to the $\mathrm{Z}$ and $\mathrm{Z}$-EDOZ model predictions in Fig. 22a. Both models predict less volume above the preimpact surface than observed. Bulking the ballistic ejecta volume by a factor of two $\left(V_{\mathrm{Up}}+2 V_{\mathrm{BE}}\right)$ also falls short of the data. Around small simple craters, the near-rim ejecta will experience moderate bulking from fracturing, similar to the $5-10 \%$ bulking observed in the breccia lens within terrestrial crater cavities (Grieve and Garvin 1984). Distal ejecta around simple craters and ejecta surrounding large complex craters are heavily fractured and incorporate surface materials into the ejecta flow through ballistic sedimentation (Oberbeck 1975). The ejecta around the $1.8 \mathrm{~km}$ diameter Lonar crater, which formed within the Deccan Traps, India, displays features similar to the ground-hugging flow around Martian craters (Fudali et al. 1980; Stewart et al. 2005). At Lonar, the volume of the distal ejecta is about $30-40 \%$ larger than the bulk volume of the undisturbed country rock. Thus, increasing the total ejecta volume by a factor of 2 is a generous upper limit.

The relative contribution of $V_{\mathrm{BE}}$ to $V_{\mathrm{Z}-\mathrm{Above}}$ is shown in Fig. 22b. The volume of the continuous ejecta blanket around Martian craters was measured using an uplift profile of the form $h=0.5 H_{\mathrm{R}}\left(r / R_{\mathrm{R}}\right)^{-5.5}$. The $\mathrm{Z}$ and Z-EDOZ models predict lower values of $V_{\text {Ejecta }} / V_{\text {Above }}$ than observed, and the uplift 


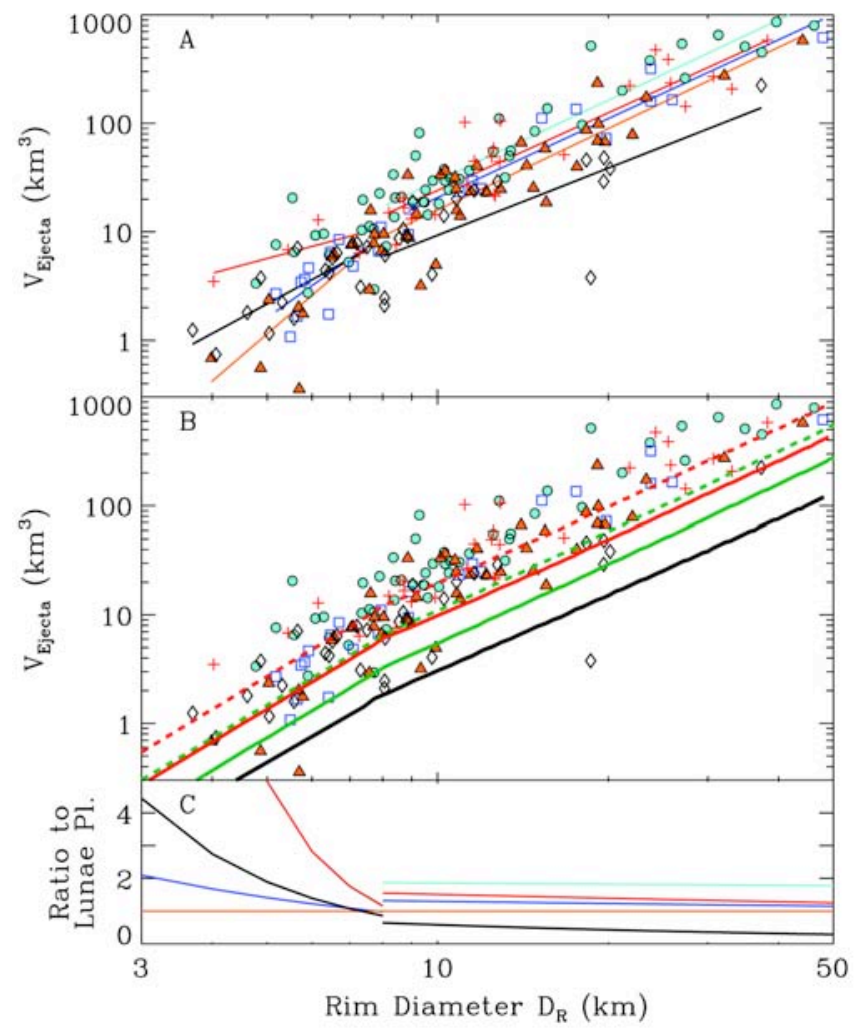

Fig. 21. a) Power law fits to the estimated ejecta volume. b) Ejecta volume predictions for original $\mathrm{Z}$ model (solid black line), Z-EDOZ model (solid green line), and Z-EDOZ model with volume increased by a factor of 2 (dashed green line). Ejecta volume (solid red line) and twice ejecta volume (dashed red line) for Z-EDOZ model with alternate crater size scaling factor $C_{\mathrm{D}} C_{\mathrm{R}}=1.4 . Z=2.7$ in all cases. c) Ratio of power law fits in (a). Note fit to Utopia overlaps with fit to Acidalia. Utopia basin = circles; Isidis basin = squares; Acidalia Planitia = crosses; Lunae Planum = triangles; Solis Planum = diamonds.

profile requires some scrutiny. In the Z-EDOZ model, the height of the uplifted surface is about equal to the thickness of the ejecta at the final crater rim, in good agreement with the uplift profile coefficient of 0.5 used to analyze the data. Using a paraboloid transient cavity and $Z=2.7$, the model slope of the uplifted surface is a -3 power law. If the uplifted surface occupies half the observed rim height, then a -3 power law lies above the observed crater topographic profiles near the crater rim. Note the steep exterior rim slopes in Fig. 11 and the "moat-like" depression around the crater rim in the example Utopian crater profile. Some of the uplifted surface may have slumped, moving outward from the crater rim, or been eroded as part of the ejecta emplacement process (e.g., Schultz and Gault 1979). Alternatively, the uplift profile predicted by the Z-EDOZ model is too high for Martian craters. The latter hypothesis is particularly problematic as the volume of the continuous ejecta blanket must increase as a result to match the measurements of $V_{\text {Above }}$. A -5.5 power law to analyze the data was used to maintain positive ejecta

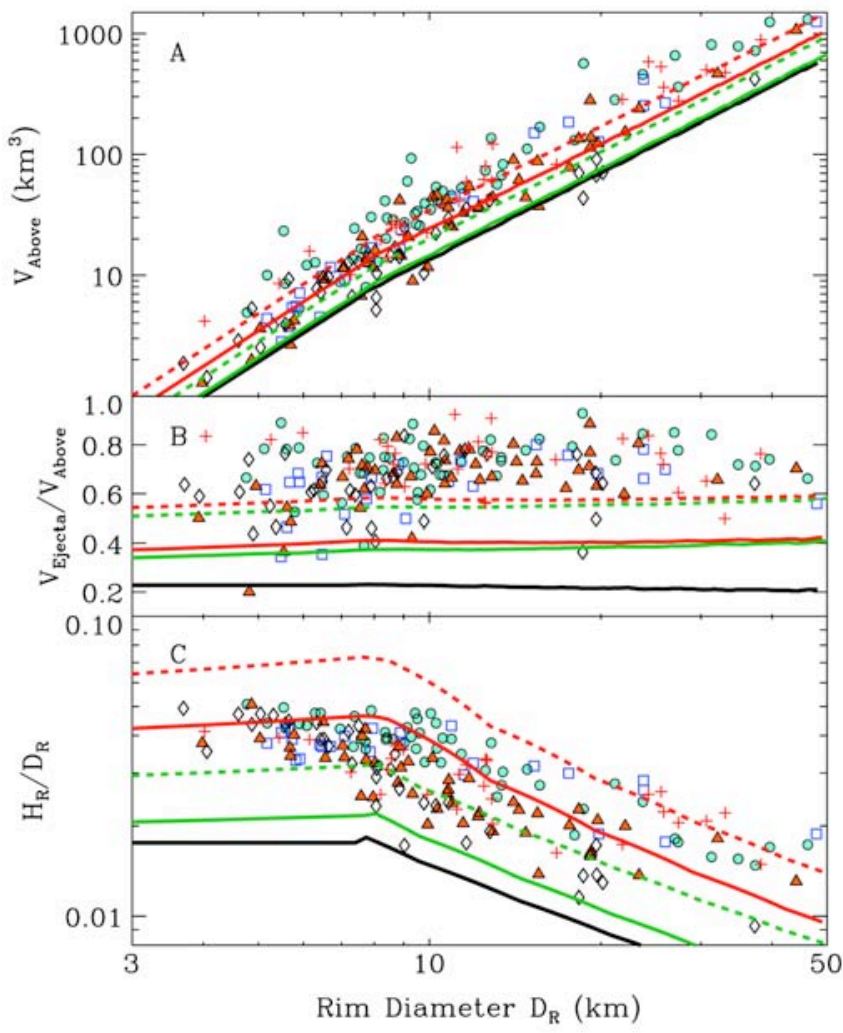

Fig. 22. $\mathrm{Z}$ model predictions compared to crater geometry measurements for (a) $V_{\text {Above }}=V_{\text {Uplift }}+V_{\text {Ejecta }}$, (b) $V_{\text {Ejecta }} / V_{\text {Above, and }}$ (c) rim height-rim diameter ratio. Original $Z$ model (solid black line), Z-EDOZ model (solid green line), and Z-EDOZ model with ejecta volume increased by a factor of 2 (dashed green line). Z-EDOZ model (solid red line) and Z-EDOZ model with twice ejecta volume (dashed red line) using alternate crater size scaling factor $C_{\mathrm{D}} C_{\mathrm{R}}=1.4$. $Z=2.7$ in all cases. Utopia basin = circles; Isidis basin $=$ squares; Acidalia Planitia = crosses; Lunae Planum = triangles; Solis Planum $=$ diamonds.

throughout the ejecta blanket, but this may have led to an overestimate of ejecta volume. None of the fresh crater profiles in Fig. 11 display simple ejecta profiles similar to the pure ballistic emplacement shown in Fig. 20. The steep nearrim topography may be a result of incorporation of the uplifted surface into the horizontal radial flow of the ejecta blanket, and the measured $V_{\text {Ejecta }}$ includes a component of uplifted material.

The Z-EDOZ model also predicts the height of the final crater rim, assuming ballistic ejecta and no postcrater formation relaxation. The sum of the model uplifted surface and ejecta thickness is shown with the crater rim height measurements, normalized to the final crater rim diameter in Fig. 22c. Again the original $\mathrm{Z}$ and Z-EDOZ models fall short of the data, and increasing the Z-EDOZ model rim ejecta thickness by a factor of two reaches the lower range of the observations.

Therefore, we find that the original $\mathrm{Z}$ and $\mathrm{Z}$-EDOZ models developed for terrestrial impact and explosion craters 
do not provide a good fit to fresh Martian impact craters. Note that the parameters controlling the distribution of ejecta are: $Z, d_{\mathrm{Z}} \sim D_{\mathrm{P}}$, the ejecta velocity scaling exponent $m$, and the scaling from the transient to final crater diameter $C_{\mathrm{D}} C_{\mathrm{R}}$. The values of $Z$ and $m$ are well constrained to lie between 2.5 and 3.0 and the model predictions are similar over this range. The diameter of the projectile $D_{\mathrm{P}}$ is derived from the transient crater diameter using Equation 2 using the mean impact velocity on Mars. Varying the center of the flow field over $0.5 D_{\mathrm{P}}<d_{\mathrm{Z}}<1.5 D_{\mathrm{P}}$ produces very similar results as presented in Figs. 21 and 22.

On the other hand, the results of the $\mathrm{Z}$ and Z-EDOZ models are very sensitive to the scaling constants $C_{\mathrm{D}} C_{\mathrm{R}}$, which relate the transient crater surface diameter to the final crater rim diameter. As can be seen in Fig. 20, the amount of ballistic ejecta in the continuous ejecta blanket depends significantly on the final rim radius. In the standard scaling laws presented in the "Crater Scaling Relationships" section, $C_{\mathrm{D}} C_{\mathrm{R}}=1.2 \times 1.3=1.56$. Formation of transient crater cavities has been extensively studied in laboratory experiments and numerical simulations (e.g., O'Keefe and Ahrens 1993; Schmidt and Housen 1987). However, the final stage of crater formation, the collapse of the transient cavity to the final crater cavity, is not well understood (Melosh and Ivanov 1999). Using the crater geometry measurements, we can constrain the scaling from transient to final crater diameters on Mars. Recall that $C_{\mathrm{D}}$ is derived for the craters in this study by fitting crater cavity volume and the transient cavity volume collapse coefficient (Equation 9). The fitted values of $C_{\mathrm{D}}$ typically lie between 1.1 and 1.2. The ratio between the rim diameter and surface diameter for simple craters, $C_{\mathrm{R}}$, is measured to lie between 1.15 and 1.2 (Fig. 17). If the observed $D_{\mathrm{R}} / D_{\mathrm{S}}$ ratio has not been significantly modified, the scaling coefficient $C_{\mathrm{D}} C_{\mathrm{R}}$ is about 1.4 for the freshest Martian impact craters.

The predictions of the Z-EDOZ model with $C_{\mathrm{D}} C_{\mathrm{R}}=1.4$ are shown as red lines in Figs. 21 and 22. Using the new scaling factor, the Z-EDOZ model produces a much better fit to the observations. The calculated range for $V_{\text {Above }}$ are in good agreement with the data. Note that the rim height predictions around simple craters are best fit by negligible bulking of the ejecta, which is expected around the rims of small craters. On the other hand, the rim heights of larger craters are better fit with significant ejecta bulking, which is a result of the increased fragmentation of ejecta landing near the final rim of complex craters. However, the predicted value of $V_{\text {Ejecta }}$ is less than measured, even when bulking is taken into account. The steep near rim topography indicates that, even with the new crater size scaling factor, some of the uplifted material must have been incorporated in the near-rim ejecta flow.

Based on comparison to the rim heights, ejecta volumes, and uplifted volumes on both highland and lowland terrains, a crater size scaling factor of $C_{\mathrm{D}} C_{\mathrm{R}}=1.4$ and the Z-EDOZ model with $d_{\mathrm{z}} \sim 1 D_{\mathrm{P}}$ and $Z=2.7$ may be used to predict the volumes of ejecta and uplifted material around fresh Martian craters. The refined model represents the first observationally constrained set of scaling laws for craters on Mars. The model provides a reliable set of initial parameters for studies of the dynamics of the ejecta blanket emplacement processes and the origin of fluidized ejecta morphologies on Mars.

Alternatively, the poor fit of the Z-EDOZ model with $C_{\mathrm{D}} C_{\mathrm{R}}=1.56$ could suggest that Martian ejecta blankets are not well characterized by ballistic emplacement. In order to match the observed geometric properties of Martian craters, the volume of material in the continuous ejecta blanket must draw on both the distal ejecta with ballistic range $>3 R_{\mathrm{R}}$ and proximal ejecta that land between the transient and final crater diameters. The observed continuous ejecta blanket has a volume almost equal to the entire predicted excavation volume. The high ejection velocities near the impact point result in large ballistic range. For example, the ballistic ejecta with a range between $3 R_{\mathrm{R}}$ and $6 R_{\mathrm{R}}$ have a volume of only $1 / 3 V_{\mathrm{BE}} \sim 1 / 9 V_{\mathrm{EXC}}$. It is unlikely that the atmosphere can collect a significant fraction of the high velocity distal ejecta. Ejecta that lands near the transient crater rim may also contribute to the continuous ejecta blanket by horizontal motion away from the transient crater rim before the collapse to the final crater diameter. Again, it is unlikely that a significant fraction of ejecta landing within the final crater diameter contributes to the continuous ejecta blanket because the ejection and ballistic flight times are comparable to the crater collapse time (Melosh and Ivanov 1999), and there would be little time for significant horizontal flow before crater collapse. Finally, the resistance of the freshest ejecta blankets to eolian erosion suggests that the bulk ejecta cannot be too porous and friable. Therefore, volume of the continuous ejecta blanket cannot be explained solely by concentration of the excavated ejecta, and the standard size scaling laws require some refinement to match the observations.

\section{CONCLUSIONS}

Using the Mars Orbiter Laser Altimeter data set, we have measured the geometric properties of fresh craters in highland and lowland plains to investigate the emplacement processes of fluidized ejecta blankets and regional differences in the strength of the upper crust and crater collapse processes. Crater geometries provide unique insights into the properties of the Martian subsurface, and quantitative differences between terrains may be mapped using the geometry of fresh Martian craters. The major findings of this study are:

1. Using simulated craters on Martian background terrains, we demonstrate that the MOLA data has sufficient resolution to measure fresh crater geometries with high precision and accuracy on all craters with $D_{\mathrm{R}} \geq 6 \mathrm{~km}$, and 
some craters as small as $D_{\mathrm{R}}=2 \mathrm{~km}$. Robust testing of the HMars crater measurement toolkit shows no systematic errors. Measurement errors are dominated by uneven background terrains.

2. In this study of $3-50 \mathrm{~km}$ rim diameter fresh craters on highland and lowland plains, we resolve significant regional differences in crater depth and cavity volumes. Simple lowland craters are 1.5-2.0 times deeper $\left(\geq 5 \sigma_{0}\right.$ difference) with $>50 \%$ larger cavities $\left(\geq 2 \sigma_{0}\right)$ compared to highland craters of the same diameter. Rim heights and the volume of material above the preimpact surface are slightly larger in the lowlands over most of the size range studied.

3. This work presents quantitative analyses of crater geometries to infer regional differences in subsurface properties. Using crater scaling laws for the volume of the transient crater cavity, we conclude that the freshest lowland craters in this study preserve a larger volume fraction $(45-70 \%)$ of the transient cavity compared to highland craters $(25-50 \%)$. Therefore, the effective strength of the upper crust in the lowland plains is stronger than in the highland plains. The presence of large simple craters up to $10.5 \mathrm{~km}$ in rim diameter in Utopia indicate that the effective yield strength of the upper several kilometers is similar to competent rock (approximately 9-12 $\mathrm{MPa}$ ). In Isidis and Acidalia, similar effective strength is inferred from similar depthto-diameter ratios and cavity volumes. Unlike lowland craters, the geometries of fresh highland simple craters grade smoothly to large, gravity-dominated crater sizes. Based on previous studies using Viking data (Pike 1988), the transition from strength- to gravity-dominated craters in the highlands may be as small as about $3-5 \mathrm{~km}$, implying effective strengths of about 3-6 $\mathrm{MPa}$, in between the range of values for soils and competent rock. The large simple craters in Utopia reflect the strength of the Noachian infill in the Utopia basin. The weaker highland materials are consistent with weak, highly fractured, layered, and possibly volatile-rich Noachian deposits.

4. Standard crater scaling laws and the Z-EDOZ crater excavation model underpredict the volume of the continuous ejecta blanket, volume of uplifted material, and the rim height by a factor of about 3 . Bulking and concentration of ejected materials by nonballistic processes cannot explain the discrepancy between the model and observations.

5. Using the geometry measurements of fresh Martian craters and analysis of crater collapse, we revise the scaling factor between the transient crater surface diameter and final crater rim diameter to $C_{\mathrm{D}} C_{\mathrm{R}}=1.4$. Comparisons between the predicted volumes of ejecta and uplifted materials indicate significant deviations from ballistic emplacement, including evidence for postemplacement horizontal flow and incorporation of surface materials into the ejecta flow.

6. The crater geometry measurements are well-fit by the revised crater size scaling factor of $C_{\mathrm{D}} C_{\mathrm{R}}=1.4$ and the $Z$-EDOZ model with $Z=2.7$ and the center of flow at a depth of about 1 projectile diameter $\left(d_{\mathrm{Z}} \sim 1 D_{\mathrm{P}}\right)$. This crater scaling and excavation model may be used to predict the volumes of ejecta and uplifted material around fresh Martian craters. The refined model represents the first observationally constrained set of scaling laws for Mars. The model provides a reliable set of initial parameters for studies of the dynamics of the ejecta blanket emplacement processes and the origin of fluidized ejecta morphologies on Mars.

Acknowledgments-This work was supported by NASA grant NAG5-13474. The authors thank Vaidya G. Rajagopalan, Zain Khalid, and Ben Black for their assistance with crater measurements. We appreciate the thoughtful reviews by J. Boyce and J. Garvin, which improved this work.

\section{Editorial Handling-Dr. Nadine Barlow}

\section{REFERENCES}

Ahrens T. J. and O'Keefe J. D. 1987. Impact on the Earth, ocean and atmosphere. International Journal of Impact Engineering 5:1332 .

Anderson J. L. B., Schultz P. H., and Heineck J. T. 2004. Experimental ejection angles for oblique impacts: Implications for the subsurface flow-field. Meteoritics \& Planetary Science 39:303-320.

Barlow N., Stewart S., and Barnouin-Jha O. 2005. The role of volatiles and atmospheres on Martian impact craters (abstract). Eos 86:433.

Barlow N. G., Boyce J. M., Costard F. M., Craddock R. A., Garvin J. B., Sakimoto S. E. H., Kuzmin R. O., Roddy D. J., and Soderblom L. A. 2000. Standardizing the nomenclature of Martian impact crater ejecta morphologies. Journal of Geophysical Research 105:26,733-26,738.

Barlow N. G. and Bradley T. L. 1990. Martian impact craters: Correlations of the ejecta and interior morphologies with diameter, altitude, and terrain. Icarus 87:156-179.

Barnouin-Jha O. S., Baloga S., and Glaze L. 2005. Comparing landslides to fluidized crater ejecta on Mars. Journal of Geophysical Research, doi:10.1029/2003JE002214.

Barnouin-Jha O. S. and Schultz P. H. 1998. Lobateness of impact ejecta deposits from atmospheric interactions. Journal of Geophysical Research 103:25,739-25.756.

Black B. A. and Stewart S. T. Forthcoming. Impact crater geometries provide evidence for ice-rich layers at low latitudes on Mars. Journal of Geophysical Research.

Bottke W. F., Nolan M. C., Greenberg R., and Kolvoord R. A. 1994. Collisional lifetimes and impact statistics of near-Earth asteroids. In Hazards due to comets and asteroids, edited by Gehrels T. Tucson, Arizona: The University of Arizona Press. pp. 337-357.

Boyce J. M., Mouginis-Mark P., and Garbeil H. 2005a. Ancient oceans in the northern lowlands of Mars: Evidence from impact crater depth/diameter relationships. Journal of Geophysical Research 110, doi:10.1029/2004JE002328. 
Boyce J. M., Mouginis-Mark P., Garbeil H., and Tornabene L. L. 2006. Deep impact crater in the Isidis and southwestern Utopia Planitia regions of Mars: High target material strength as a possible cause. Geophysical Research Letters 33, doi:10.1029/ 2005 GL024462.

Boyce J. M., Mouginis-Mark P. J., Garbeil H., and Soderblom L. A. 2005b. History of major degradational events in the highlands of Mars: Preliminary results from crater depth/diameter measurements (abstract \#1055). 36th Lunar and Planetary Science Conference. CD-ROM.

Buczkowski D. L., Frey H. V., Roark J. H., and McGill G. E. 2005. Buried impact craters: A topographic analysis of quasi-circular depressions, Utopia basin, Mars. Journal of Geophysical Research 110, doi:10.1029/2004JE002324.

Carr M. H., Crumpler L. S., Cutts J. A., Greeley R., Guest J. E., and Masursky H. 1977. Martian impact craters and emplacement of the ejecta by surface flow. Journal of Geophysical Research 82: 4055-4065.

Cintala M. J. and Mouginis-Mark P. J. 1980. Martian fresh crater depths: More evidence for subsurface volatiles? Geophysical Research Letters 7:329-332.

Croft S. K. 1980. Cratering flow fields: Implications for the excavation and transient expansion stages of crater formation. Proceedings, 11th Lunar and Planetary Science Conference. pp. 2347-2378.

Forsberg-Taylor N. K., Howard A. D., and Craddock R. A. 2004. Crater degradation in the Martian highlands: Morphometric analysis of the Sinus Sabaeus region and simulation modeling suggest fluvial processes. Journal of Geophysical Research 109, doi:10.1029/2004JE002242.

Frey H., Hohner G., Wernecke A., Roark J., and Sakimoto S. 2002a. Constraining the thickness of ridged plains using relief from buried impact basins compared to exposed craters on adjacent cratered terrain (abstract \#P32A-02). 2002 American Geophysical Union Spring Meeting. CD-ROM.

Frey H. V., Doudnikoff C. E., and Mongeon A. M. 1991. Are Noachian-age ridged plains (Nplr) actually Early Hesperian in age. Proceedings, 21 st Lunar and Planetary Science Conference. pp. 635-644.

Frey H. V., Roark J. H., Shockey K. M., Frey E. L., and Sakimoto S. E. H. 2002b. Ancient lowlands on Mars. Geophysical Research Letters 29, doi:0.1029/2001GL013832.

Frey H. V., Sakimoto S. E. H., and Roark J. H. 1998. MOLA topography and the Isidis basin: Constraints on basin center and ring diameters (abstract \#1631). 29th Lunar and Planetary Science Conference. CD-ROM.

Fudali R. F., Milton D. J., Fredriksson K., and Dube A. 1980. Morphology of Lonar crater, India: Comparisons and implications. The Moon and the Planets 23:493-515.

Garvin J. B. and Frawley J. J. 1998. Geometric properties of Martian impact craters: Preliminary results from the Mars Orbiter Laser Altimeter. Geophysical Research Letters 25:4405-4408.

Garvin J. B., Sakimoto S. E. H., and Frawley J. J. 2003. Craters on Mars: Global geometric properties from gridded MOLA topography (abstract \#3277). The Sixth International Conference on Mars. CD-ROM.

Garvin J. B., Sakimoto S. E. H., Frawley J. J., and Schnetzler C. 2000. North polar region craterforms on Mars: Geometric characteristics from the Mars Orbiter Laser Altimeter. Icarus 144:329-352.

Garvin J. B., Sakimoto S. E. H., Frawley J. J., and Schnetzler C. 2002. Global geometric properties of Martian impact craters (abstract \#1255). 33rd Lunar and Planetary Science Conference. CD-ROM.
Gault D. E. and Greeley R. 1978. Exploratory experiments of impact craters formed in viscous-liquid targets: Analogs for Martian rampart craters? Icarus 34:486-495.

Grieve R. A. F. and Garvin J. B. 1984. A geometric model for excavation and modification at terrestrial simple impact craters. Journal of Geophysical Research 89:11,561-11,572.

Hamilton V. E. and Christensen P. R. 2005. Evidence for extensive, olivine-rich bedrock on Mars. Geology 33:433-436.

Hamilton V. E., Christensen P. R., McSween H. Y., Jr., and Bandfield J. L. 2003. Searching for the source regions of Martian meteorites using MGS TES: Integrating Martian meteorites into the global distribution of igneous materials on Mars. Meteoritics \& Planetary Science 38:871-885.

Head J. N., Melosh H. J., and Ivanov B. A. 2002. Martian meteorite launch: High-speed ejecta from small craters. Science 298:17521756.

Hoefen T. M., Clark R. N., Bandfield J. L., Smith M. D., Pearl J. C., and Christensen P. R. 2003. Discovery of olivine in the Nili Fossae region of Mars. Science 302:627-630.

Holsapple K. A. 1993. The scaling of impact processes in planetary sciences. Annual Review of Earth and Planetary Sciences 21: 333-373.

Holsapple K. A. and Schmidt R. M. 1982. On the scaling of crater dimensions 2. Impact processes. Journal of Geophysical Research 87:1849-1870.

Holsapple K. A. and Schmidt R. M. 1987. Point-source solutions and coupling parameters in cratering mechanics. Journal of Geophysical Research 92:6350-6376.

Horner V. M. and Greeley R. 1982. Pedestal craters on Ganymede. Icarus 51:549-562.

Ivanov B. A. 1996. Spread of ejecta from impact craters and the possibility of estimating the volatile content of the Martian crust. Solar System Research 30:43-58.

Kuz'min R. O., Bobina N. N., Zabalueva E. V., and Shashkina V. P. 1988. Structural inhomogeneities of the Martian cryolithosphere. Solar System Research 22:121-133.

Lee D. T. and Schachter B. J. 1980. Two algorithms for constructing a Delaunay triangulation. International Journal of Computer and Information Science 9:219-242.

Malin M. C. and Edgett K. S. 2000. Sedimentary rocks of early Mars. Science 290:1927-1937.

Maxwell D. E. 1973. Cratering flow and crater prediction methods. Technical Memorandum \#TCAM 73-17. San Leandro, California: Physics International. 50 p.

Maxwell D. E. 1977 Simple Z model of cratering, ejection, and the overturned flap. In Impact and explosion cratering, edited by Roddy D. J., Pepin R. O., and Merrill R. B. New York: Elmsford. pp. 983-1022.

Melosh H. J. 1989. Impact cratering: A geologic process. New York: Oxford University Press. 253 p.

Melosh H. J. 1998. Crater scaling program. http:// www.lpl.arizona.edu/tekton/crater.html.

Melosh H. J. and Ivanov B. A. 1999. Impact crater collapse. Annual Review of Earth and Planetary Sciences 27:385-415.

Meresse S., Costard F., and Mangold N. 2005. Evidence for removal episode on northern plains from the Martian fluidized ejecta volume (abstract \#1748). 36th Lunar and Planetary Science Conference. CD-ROM.

Mouginis-Mark P. 1981. Ejecta emplacement and modes of formation of Martian fluidized ejecta craters. Icarus 45:60-76.

Mouginis-Mark P. J. 1978. Morphology of Martian rampart craters. Nature 272:691-694.

O'Keefe J. D. and Ahrens T. J. 1993. Planetary cratering mechanics. Journal of Geophysical Research 98:17,011-17,028. 
Oberbeck V. R. 1975. The role of ballistic erosion and sedimentation in lunar stratigraphy. Reviews of Geophysics and Space Physics $13: 337-362$.

Piekutowski A. J. 1977. Cratering mechanisms observed in laboratory-scale high-explosive experiments. In Impact and explosion cratering, edited by Roddy D. J., Pepin R. O., and Merrill R. B. New York: Pergamon Press. pp. 67-102.

Pierazzo E. and Melosh H. J. 2000. Melt production in oblique impacts. Icarus 145:252-261.

Pierazzo E., Vickery A. M., and Melosh H. J. 1997. A reevaluation of impact melt production. Icarus 127:408-423.

Pike R. J. 1977. Size-dependence in the shape of fresh impact craters on the Moon. In Impact and explosion cratering, edited by Roddy D. J., Pepin R. O., and Merrill R. B. New York: Pergamon Press. pp. 489-509.

Pike R. J. 1980. Control of crater morphology by gravity and target type: Mars, Earth, Moon. Proceedings, 11th Lunar and Planetary Science Conference. pp. 2159-2189.

Pike R. J. 1988. Geomorphology of impact craters on Mercury. In Mercury, edited by Vilas F., Chapman C. R., and Matthews M. S. Tucson, Arizona: The University of Arizona Press. pp. $165-273$.

Quaide W. L. and Oberbeck V. R. 1968. Thickness determinations of lunar surface layer from lunar impact craters. Journal of Geophysical Research 73:5247-5270.

Rodriguez J. A. P., Sasaki S., Dohm J. M., Tanaka K. L., Strom B., Kargel J., Kuzmin R., Miyamoto H., Spray J. G., Fairen A. G., Komatsu G., Kurita K., and Baker V. 2005. Control of impact crater fracture systems on subsurface hydrology, ground subsidence, and collapse, Mars. Journal of Geophysical Research 110, doi:10.1029/2004JE002365

Schmidt R. M. and Housen K. R. 1987. Some recent advances in the scaling of impact and explosion cratering. International Journal of Impact Engineering 5:543-560.

Schultz P. H. 1992. Atmospheric effects on ejecta emplacement. Journal of Geophysical Research 97:11,623-11,662.

Schultz P. H. and Gault D. E. 1979. Atmospheric effects on Martian ejecta emplacement. Journal of Geophysical Research 84:76697687.

Scott D. H. and Tanaka K. L. 1986. Geologic map of the western equatorial region of Mars. U.S. Geological Survey Miscellaneous Investigations Series Map I-1802-A. Scale 1: $15,000,000$.

Searls M. L. and Phillips R. J. 2004. Mechanics of Utopia basin on Mars (abstract \#1822). 35th Lunar and Planetary Science Conference. CD-ROM.

Smith D. E., Zuber M. T., Frey H. V., Garvin J. B., Head J. W., Muhleman D. O., Pettengill G. H., Phillips R. J., Solomon S. C.,
Zwally H. J., Banerdt W. B., Duxbury T. C., Golombek M. P., Lemoine F. G., Neumann G. A., Rowlands D. D., Aharonson O., Ford P. G., Ivanov A. B., Johnson C. L., McGovern P. J., Abshire J. B., Afzal R. S. and Sun X. L. 2001. Mars Orbiter Laser Altimeter: Experiment summary after the first year of global mapping of Mars. Journal of Geophysical Research 106:23,68923,722.

Smith D. E., Zuber M. T., Solomon S. C., Phillips R. J., Head J. W., Garvin J. B., Banerdt W. B., Muhleman D. O., Pettengill G. H., Neumann G. A., Lemoine F. G., Abshire J. B., Aharonson O., Brown C. D., Hauck S. A., Ivanov A. B., McGovern P. J., Zwally H. J., and Duxbury T. C. 1999. The global topography of Mars and implications for surface evolution. Science 284:1495-1503.

Stewart S. T., Maloof A. C., Newsom H. E., Wright S. P., Louzada K. L., and Weiss B. P. 2005. Field observations of groundhugging ejecta flow at Lonar crater, India (abstract \#3045). Workshop on the Role of Volatiles and Atmospheres on Martian Impact Craters. CD-ROM.

Stewart S. T., O'Keefe J. D., and Ahrens T. J. 2001. The relationship between rampart crater morphologies and the amount of subsurface ice (abstract \#2092). 32nd Lunar and Planetary Science Conference.

Stewart S. T., O'Keefe J. D., and Ahrens T. J. 2004. Impact processing and redistribution of near-surface water on Mars. In Shock compression of condensed matter 2003, edited by Furnish M. D., Gupta Y. M., and Forbes J. W. Melville, New York: American Institute of Physics. pp. 1484-1487.

Thomsen J. M., Austin M. G., Ruhl S. F., Schultz P. H., and Orphal D. L. 1979. Calculational investigation of impact cratering dynamics: Early time material motions. Proceedings, 10th Lunar and Planetary Science Conference. pp. 2741-2756.

Thomsen J. M., Austin M. G., and Schultz P. H. 1980. The development of the ejecta plume in a laboratory-scale impact cratering event (abstract). Proceedings, 11th Lunar and Planetary Science Conference. pp. 1146-1148.

Thomson B. J. and Head J. W. 1999. Utopia basin, Mars: A new assessment using Mars Orbiter Laser Altimeter (MOLA) data (abstract \#1894). 30th Lunar and Planetary Science Conference. CD-ROM.

Thomson B. J. and Head J. W. 2001. Utopia basin, Mars: Characterization of topography and morphology and assessment of the origin and evolution of basin internal structure. Journal of Geophysical Research 106:23,209-23,230.

Valiant G. J. and Stewart S. T. 2004. Martian surface properties: Inferences from resolved differences in crater geometries (abstract \#1293). 35th Lunar and Planetary Science Conference. CD-ROM.

Appendix A. Variables.

\begin{tabular}{ll}
\hline Variable & Description \\
\hline$c$ & Cutoff parameter for fresh crater definition \\
$C_{2}, C_{3}$ & $\pi_{2}, \pi_{3}$ scaling constants \\
$C_{\mathrm{D}}$ & Ratio between $D_{\mathrm{ST}}$ and $D_{\mathrm{S}}$ (simple craters) \\
$C_{\mathrm{R}}$ & Ratio between $D_{\mathrm{R}}$ and $D_{\mathrm{S}}$ (simple craters) \\
$C_{\mathrm{V}}$ & Crater volume collapse coefficient (simple craters) \\
$D_{\mathrm{P}}$ & Projectile diameter \\
$d_{\mathrm{R}}$ & Depth from rim \\
$D_{\mathrm{R}}, D_{\mathrm{S}}$ & Rim diameter, surface diameter \\
$d_{\mathrm{S}}$ & Surface depth \\
$d_{\mathrm{ST}}$ & Transient crater surface depth \\
$D_{\mathrm{ST}}$ & Transient crater surface diameter \\
\hline
\end{tabular}


Appendix A. Continued. Variables.

\begin{tabular}{|c|c|}
\hline Variable & Description \\
\hline$d_{\mathrm{Z}}$ & Depth to flow center in Z-EDOZ model \\
\hline$D^{*}$ & Transition rim diameter between strength and gravity regimes \\
\hline$F_{\mathrm{d}}$ & Observed maximum crater surface depth, as function of diameter and region \\
\hline$F_{\mathrm{H}_{\mathrm{B}}}^{\mathrm{d}_{\mathrm{s}}}$ & Observed maximum rim height, as function of diameter and region \\
\hline$g$ & Surface gravity \\
\hline$h_{\mathrm{u}}$ & Height of uplifted preimpact surface \\
\hline$H_{\mathrm{R}}$ & Rim height \\
\hline $\mathrm{m}$ & Ejection velocity scaling exponent \\
\hline$m_{\mathrm{P}}$ & Projectile mass \\
\hline$N_{\mathrm{R}}$ & Number of rim points from MOLA tracks \\
\hline $\mathrm{r}$ & Radial distance from crater center line; polar coordinate for Z-EDOZ model \\
\hline$R_{\mathrm{h}}$ & Distance between flow center, $d_{\mathrm{Z}}$, and uplift location $\left(r_{\mathrm{u}}, h_{\mathrm{u}}\right)$ \\
\hline$R_{\mathrm{R}}, R_{\mathrm{S}}$ & Rim radius, surface radius \\
\hline$R_{\mathrm{ST}}$ & Surface radius of transient cavity \\
\hline$r_{\mathrm{u}}$ & Surface radius at uplift elevation $h_{\mathrm{u}}$ \\
\hline$V_{\text {Above }}$ & Combined volume of ejecta and uplift \\
\hline$V_{\mathrm{BE}}$ & Volume of ballistic ejecta with range between $1 R_{\mathrm{R}}$ and $3 R_{\mathrm{R}}$ \\
\hline$V_{\text {Cavity }}$ & Cavity volume below preimpact surface \\
\hline$v_{\mathrm{e}}$ & Ejection velocity for Z-EDOZ model stream tube \\
\hline$V_{\text {Ejecta }}$ & Volume of ejecta \\
\hline$V_{\mathrm{EXC}}$ & Total excavated volume \\
\hline$v_{\mathrm{i}}$ & Projectile impact velocity \\
\hline$V_{\text {Rim }}$ & Cavity volume below rim \\
\hline$v_{\mathrm{ST}}$ & Ejection velocity for stream tube at transient crater radius \\
\hline$V_{\mathrm{T}}$ & Volume of transient crater cavity below preimpact surface \\
\hline$V_{\mathrm{Up}}$ & Volume of uplifted material between $1 R_{\mathrm{R}}$ and $3 R_{\mathrm{R}}$ \\
\hline$V_{\mathrm{Z}-\text { Above }}$ & Combined uplift and ejecta volume between $1 R_{\mathrm{R}}$ and $3 R_{\mathrm{R}}$ predicted by Z-EDOZ model \\
\hline$V_{\mathrm{Z}, \mathrm{r}_{\mathrm{S}}}$ & Excavated volume by a Z-EDOZ trajectory emerging at radius $r_{\mathrm{S}}$ \\
\hline $\mathrm{Y}^{2, \mathrm{i}_{\mathrm{S}}}$ & Effective yield strength of surface \\
\hline Z & $\mathrm{Z}$ and Z-EDOZ model parameter \\
\hline$\beta$ & $\pi_{2}$ scaling exponent \\
\hline$\delta$ & Angle from flow center to uplift point in Z-EDOZ model \\
\hline$\Delta$ & Angle between the horizontal at depth $d_{\mathrm{Z}}$ and intersection of stream tube at surface \\
\hline$\theta$ & Polar coordinate in Z-EDOZ model \\
\hline$\mu$ & Scaling exponent coupling parameter \\
\hline$\pi_{2}$ & Inverse Froude number \\
\hline$\pi_{3}$ & Inverse Cauchy number \\
\hline$\pi_{\mathrm{D}}$ & Nondimensional crater diameter \\
\hline$\pi_{\mathrm{V}}$ & Nondimensional crater volume \\
\hline$\rho$ & Density \\
\hline$\sigma$ & $\pi_{3}$ scaling exponent \\
\hline$\sigma_{\mathrm{m}}$ & Systematic measurement error \\
\hline$\sigma_{\mathrm{o}}$ & Observed measurement scatter around a given fit \\
\hline$\phi$ & Impact angle from surface \\
\hline$\varphi$ & Ejection angle from surface \\
\hline
\end{tabular}

